NBER WORKING PAPER SERIES

\title{
INCLUDING HEALTH INSURANCE IN POVERTY MEASUREMENT: THE IMPACT OF MASSACHUSETTS HEALTH REFORM ON POVERTY
}

\author{
Sanders Korenman \\ Dahlia K. Remler \\ Working Paper 21990 \\ http://www.nber.org/papers/w21990 \\ NATIONAL BUREAU OF ECONOMIC RESEARCH \\ 1050 Massachusetts Avenue \\ Cambridge, MA 02138 \\ February 2016
}

We thank Rob Patrizzo for excellent research assistance, supported by a Baruch College School of Public Affairs Graduate Assistantship. We thank Jonathan Gruber, Michael Norton of the Massachusetts Health Connector and Keith Ericsson for assistance obtaining the Massachusetts health plan data used in this paper. We thank Neil Bennett, Rebecca Blank, Richard Burkhauser, Irv Garfinkel, Thesia Garner, Diane Gibson, David Johnson, Sherry Glied, Mark Levitan, Brendan Saloner, and discussants and participants at the 2014 APPAM, 2014 ASHEcon and 2015 PAA conferences for comments on earlier drafts and useful discussions. All errors are our own. The views expressed herein are those of the authors and do not necessarily reflect the views of the National Bureau of Economic Research.

NBER working papers are circulated for discussion and comment purposes. They have not been peerreviewed or been subject to the review by the NBER Board of Directors that accompanies official NBER publications.

(C) 2016 by Sanders Korenman and Dahlia K. Remler. All rights reserved. Short sections of text, not to exceed two paragraphs, may be quoted without explicit permission provided that full credit, including (C) notice, is given to the source. 
Including Health Insurance in Poverty Measurement: The Impact of Massachusetts Health

Reform on Poverty

Sanders Korenman and Dahlia K. Remler

NBER Working Paper No. 21990

February 2016

JEL No. I13,I32

ABSTRACT

We develop and implement what we believe is the first conceptually valid health-inclusive poverty measure (HIPM) - a measure that includes health care or insurance in the poverty needs threshold and health insurance benefits in family resources-and we discuss its limitations. Building on the Census Bureau's Supplemental Poverty Measure, we construct a pilot HIPM for the under-65 population under ACA-like health reform in Massachusetts. This pilot is intended to demonstrate the practicality, face validity and value of a HIPM. Results suggest that public health insurance benefits and premium subsidies accounted for a substantial, one-third reduction in the poverty rate. Among low-income families who purchased individual insurance, premium subsidies reduced poverty by 9.4 percentage points.

Sanders Korenman

School of Public Affairs

Baruch College

City University of New York

One Bernard Baruch Way

Box D-901

New York, NY 10010

and NBER

sanders.korenman@baruch.cuny.edu

Dahlia K. Remler

School of Public Affairs

Baruch College

City University of New York

One Bernard Baruch Way

Box D-901

New York, NY 10010

and NBER

Dahlia.Remler@baruch.cuny.edu 


\section{Introduction}

The Affordable Care Act (ACA) has brought health insurance-and therefore greater access to health care and relief from the risk of financially ruinous medical expenditures—-to millions, including millions of low-income individuals. Yet neither the Census Bureau's “Official” Poverty Measure (OPM) nor its Supplemental Poverty Measure (SPM) can capture the bulk of the ACA's impact on poverty. The OPM does not include in-kind (i.e., non-cash) benefits as resources available to meet basic needs. And although the SPM greatly improves upon the OPM by including most in-kind benefits, it too excludes health insurance benefits from resources and does not include a need for health care or insurance in the poverty threshold. Instead, the SPM addresses health indirectly, by deducting from resources all out-of-pocket expenditures on medical care or insurance (MOOP) (Short 2013; Caswell and O’Hara 2010). The SPM measures whether income, net of MOOP expenditures, is sufficient to meet non-health “material” needs. Therefore, health insurance and the ACA can reduce poverty as measured by the SPM only to the extent that they reduce MOOP.

But health insurance is valuable beyond reducing MOOP. First, the insured receive valuable medical care that the uninsured do not - the access value of insurance (IOM 2002; Nyman 2003, 2004; Sommers, Long and Baicker 2014). When the uninsured forego medical care, the SPM does not measure their unmet health needs. Second, health insurance is valuable because it reduces ex ante risk, even if in a given year, ex post, care was not needed, as in the classic example of fire insurance that is valuable ex ante even when no fire occurs (Blinder 1985).

The SPM has been used to estimate how Medicaid reduces poverty by reducing MOOP. Sommers and Oellerich (2013) find that Medicaid reduces the SPM poverty rate by 0.7 
percentage point overall and by one percentage point for children, suggesting that over $\$ 400$ billion in annual Medicaid spending reduces poverty only slightly. However, these estimates capture Medicaid's impact only through reducing MOOP and miss Medicaid's ability to meet unmet health care needs. As Sommers and Oellerich write: "Beyond the program's presumed primary benefit of improved access to care and health, we find that Medicaid has significant poverty-reducing effects of a similar order of magnitude of other dedicated anti-poverty government programs” (p. 829, emphasis added). A more complete assessment of Medicaid's effects on poverty would also capture its "primary benefit."

While health care is widely perceived as a basic need, creating a valid measure of poverty that incorporates the need for health care has "bedeviled analysts since the 1970s" (NAS 1995 p. 223; see also Ellwood and Summers 1985, Ruggles 1990, Moon 1993). Without a health need in the poverty threshold, it is inconsistent to include health insurance benefits in resources (NAS 1995, p. 224).

The distortion produced by poverty measures that do not include health has grown as health care's share of government and individual expenditures has grown, most recently with the ACA (Martin et al. 2015). Drawing on insights from health economics, we argue that the ACA has also made it possible to incorporate health insurance needs and resources into poverty measurement, as we explain below.

In implementing the SPM, the Census Bureau followed closely the recommendations of a National Academy of Sciences (NAS) expert panel on poverty measurement (NAS 1995). The NAS panel struggled to include health in its recommended poverty measure, finding no valid and practical way to do so (see also Moon 1993). Including health care or insurance in the poverty measure requires putting a dollar value on health needs and on resources such as health insurance 
provided by government or employers. The key underlying barrier to including health insurance was an inability to determine the cost of insurance to a particular family (Korenman and Remler 2013); at the time, what a US family needed to spend to obtain insurance depended on health status, employment and other factors. Indeed health insurance might not have been available at any price due to preexisting conditions. Consequently, the panel recommended subtracting MOOP from resources and excluding health care/insurance from needs, resulting in a poverty measure based on the ability to meet non-health ("material") needs only. This recommendation was controversial from the outset (Cogan 1995; Bavier, 1998; Corbett 1999; Betson 2000). The NAS panel stressed that the recommended approach “...does not explicitly acknowledge a basic necessity, namely, medical care that is just as important as food and housing....and devalues the benefits of having health insurance, except indirectly” (NAS 1995, p. 236).

Moreover, the current SPM (based on the NAS approach) could become a misleading indicator of the effect of health reform. The ACA transfers large subsidies for health insurance to lower-income persons, materially affecting the distribution of income (Aaron and Burtless 2014; Burkhauser, Larrimore and Simon 2013; CBO 2012). Yet, in subtracting out-of-pocket premium payments from income and excluding the value of health insurance benefits from resources and needs, the SPM could very well indicate that the ACA has made low-income households poorer. The SPM will not register increased care for the formerly uninsured as meeting health needs nor the reduced financial risk as meeting insurance needs. The SPM captures only reductions in MOOP, if they occur. A HIPM, in contrast, captures the role of health insurance in meeting all these health care and insurance needs—access, ex ante risk reduction, and MOOP. ${ }^{1}$

\footnotetext{
${ }^{1}$ In addition, separating health from material poverty measures can result in different poverty classifications for people who make different health insurance and health care purchase decisions despite identical resources, opportunities, and health statuses.
} 
We previously analyzed the impediments to a valid Health Inclusive Poverty Measure (HIPM)—a measure that includes health needs and counts health insurance benefits as resources available to meet those needs (Korenman and Remler 2013). We showed that a valid HIPM can be constructed if health insurance is considered the basic health need and the health system has certain characteristics: universally available health insurance with premiums unrelated to health status (community rating) and caps on MOOP expenditures for care. (Since health insurance is not fungible—usable for non-health needs—-the HIPM must never value health insurance benefits more than health insurance needs.) These health system requirements are met, for citizens and legal residents, by a combination of Medicare Advantage Prescription Drug Plans and the ACA. Since ACA-like reforms took effect in Massachusetts in 2008 (Gruber 2011, Long and Masi 2009), we are able implement a HIPM for 2010 Massachusetts. A HIPM can be implemented for the US as required data become available (Pascale, Boudreaux and King 2014; CMS n.d.).

Our purpose is to demonstrate the practicality, value and face validity of a HIPM for the under-65 population, the primary beneficiaries of health reform. ${ }^{2}$ We (1) explain why ACA-like reforms make the HIPM conceptually valid; (2) demonstrate its practicality by implementing a pilot HIPM under the Massachusetts health reform; and (3) demonstrate its value by using the HIPM to assess the direct impact of health benefits on poverty rates and poverty gaps. Although we believe the HIPM to be an improvement over existing measures, we also discuss limitations.

According to our pilot HIPM, the poverty rate for the under-65 in Massachusetts in 2010 was $12.2 \%$, compared to $13.5 \%$ for the SPM. The HIPM rate was modestly lower than the SPM rate because most health insurance needs were met. However, the HIPM rate would likely be

\footnotetext{
${ }^{2}$ The treatment of the population aged 65 and older involves different institutional considerations; see Korenman and Remler (2013).
} 
much higher than the SPM in states with substantial unmet health insurance needs. Public health insurance programs reduced poverty by 3.9 percentage points, 0.6 percentage points of which is due to Massachusetts’s premium subsidies. The “cash income” HIPM poverty gap (as a percent of the HIPM poverty line) was $43.7 \%$. When we added all in-kind benefits to income, the gap fell by 26.5 percentage points, of which 3.6 points derives from employer-provided health insurance and 6.9 points from Medicaid and Medicare. Among poor persons covered by individually-purchased insurance, premium subsidies alone reduced the poverty gap by nearly 20 percentage points, from $51.5 \%$ to $32.4 \%$. These direct impacts of health insurance transfers on poverty are not captured by the OPM or SPM.

Although only illustrative, our estimates show the feasibility of constructing a poverty measure that incorporates health in both resources and needs. Thus, the ACA has made reaching this goal, which eluded researchers for decades, both possible and increasingly important. The estimates suggest that public health insurance programs and subsidies substantially reduce poverty, particularly poverty gaps. As data become available, a HIPM could show the impact on poverty of other heath policies, such as states' expanding —or failing to expand-Medicaid eligibility.

\section{When a Health Inclusive Poverty Measure Is Possible}

Our HIPM includes health insurance in the poverty threshold. This requires that health insurance be considered a basic need, no matter an individual's health status. In other words, basic health insurance is deemed essential and not wasted even if ex post an individual used little or no health care and even for someone with little ex ante expected health care usage. 
Whether or not health insurance is a need is a philosophical and political question about which people can disagree. However, it is clear that health insurance is widely considered a need since all high-income countries other than the US have universal health insurance. In the US, Medicaid, Medicare, and the ACA, particularly its insurance mandate and subsidies for those who cannot afford it, suggest that health insurance is considered a need in the US as well. Still, the lack of Medicaid expansion in some states indicates that the consensus is incomplete. Since the ACA plans and subsidies are the outcome of a political process, they arguably express a national standard for health insurance needs. Indeed, it is essentially impossible to define any need, especially a health care or insurance need, without reference to some social standard or norm. Therefore, we use the political authority of the ACA to justify our choice of a national need standard.

Some argue that, while health care is a need, health insurance is not, because uninsured poor people receive free care, through hospital uncompensated care and free clinics. But free care does not fully substitute for insurance (e.g., Dillman et al. 2014). For example, while hospitals must treat people in unstable conditions (e.g., having a heart attack) who are unable to pay, they are not required to treat those with non-acute conditions, such as many cancer patients (CMS 2003). Thus, viewing health insurance as unnecessary is equivalent to adopting a lower standard of health care need. Although we always treat insurance as the primary health care need, we recognize that free care provides implicit (inferior) insurance, and therefore conduct sensitivity analyses incorporating that resource.

The logic and practicalities of poverty measurement further justify considering health insurance to be the basic health care need. It is true that any immediate need is for health care and that care can be purchased directly, without insurance. However, the resources needed to 
provide care to a heart attack victim are not the dollars needed to buy that care, but rather insurance. The vast majority of Americans use insurance to meet their health care needs. Further, the funds needed to pay directly for health care vary tremendously by detailed health status, making it utterly impractical to determine the direct costs of needed care for a poverty threshold. In contrast, insurance covers the care needed for a wide variety of health conditions. If basic health insurance is considered a need, it is valid and straightforward to add that need to the poverty threshold since Medicare, the ACA, and similar reforms break the link between health status and resources required to meet health needs.

To understand how the ACA and Massachusetts health reforms enable construction of a HIPM, consider a health care system that makes eligibility universal for basic insurance, the "Basic Plan.” The Basic Plan covers all care deemed essential by society, so it is complete in the events, treatments and procedures covered. However, it does not fully pay for all essential care. First, people must pay part of the premium out-of-pocket (premium MOOP). But that premium is not risk-rated: it does not depend on health status. Second, the Basic Plan includes cost-sharing, such as deductibles and co-pays (nonpremium MOOP). (However, it caps cost-sharing payments.) In such a system, all essential health needs can be met with premium MOOP equal to the Basic Plan premium and nonpremium MOOP less than or equal to the Basic Plan nonpremium MOOP cap. Any premium MOOP payments above the Basic Plan premium and any nonpremium MOOP payments above the Basic Plan cap are discretionary, as socially defined. Essentially, the political process determines the Basic Plan and, in so doing, defines the basic health need.

We argue that the benchmark Silver plan provides a reasonable norm for the basic health insurance plan envisioned for the HIPM. While even that assertion may prove controversial 
(given continuing political controversy about the need for the ACA and Medicaid expansions), adopting a richer plan that requires little cost-sharing as the basic health insurance plan would be more difficult to defend.

Thus, the US political process has made accessible and affordable health insurance policies in which cost-sharing is expected (in order to reduce moral hazard). Consequently, to meet their health care needs, people also need enough income to pay for cost-sharing for necessary covered care. Therefore, in post-ACA US, needs are (1) a basic health insurance policy in which cost-sharing is expected and (2) sufficient income to pay out-of-pocket for costsharing, whatever their health status, and (3) material (i.e., non-health) needs.

\section{Implementing a HIPM}

Both the ACA and Massachusetts health reforms meet conditions for a valid HIPM.

Exchange plans cover all care deemed essential and premiums cannot be tied to health status (Focus on Health Reform 2011a). Those with low income receive premium subsidies and have lower nonpremium MOOP caps. However, the reforms fall somewhat short of universal eligibility because undocumented immigrants cannot use the exchanges, and, therefore, should be excluded from HIPM calculations

Our HIPM builds on the SPM, by adding health insurance needs to the threshold, adding any health insurance benefits received to resources, and modifying the SPM's deduction of MOOP expenditures for care. Health insurance needs are the unsubsidized premium ("full cost") of the Basic Plan. Health insurance resources include any subsidies to, direct payments for, or direct provision of health insurance by government or employers. The value of insurance benefits must never exceed the value of health needs, since health insurance benefits are nonfungible. 
Specifically, to create the HIPM:

- Add health insurance (unsubsidized premium of Basic Plan) to the SPM needs threshold

- For those with insurance from employers or government, add to SPM resources ${ }^{3}$ the net value of insurance (Basic Plan premium less required premium MOOP payment)

o But do not allow the subtraction to exceed the premium MOOP required for Basic Plan

- For those who receive premium subsidies, add the subsidy to SPM resources ${ }^{3}$

o But do not allow this addition to exceed the premium of the Basic Plan

- To incorporate the need to pay for cost-sharing, subtract actual nonpremium MOOP from resources

o But do not allow this subtraction to exceed the nonpremium MOOP cap available for the Basic Plan

The family unit is poor if resources are less than needs.

Three factors determine whether the likelihood of poverty is higher or lower under a HIPM relative to the SPM. We illustrate with an example (Table 1) with two families that are identical except that Family A has no health insurance benefits while Family B has insurance fully provided by the government. First, all else the same, adding health insurance needs (the $\$ 10,000$ Basic Plan) increases the poverty threshold from $\$ 20,000$ to $\$ 30,000$ and therefore the likelihood of HIPM poverty relative to SPM poverty.

Second, adding health insurance to resources can meet, fully or partially, the higher needs threshold. Adding the same value of health insurance to needs and resources can never make HIPM poverty less likely than the SPM poverty. In our example, according to the SPM, neither family is poor because their material resources of $\$ 22,000$ exceed the $\$ 20,000$ SPM threshold. However, under the HIPM, Family A is poor while Family B is not, because Family A has no health insurance provided while Family B has insurance fully provided.

\footnotetext{
${ }^{3}$ SPM resources before the MOOP deduction.
} 
Third, the HIPM limit on deductions for premium and nonpremium MOOP, by itself, makes HIPM poverty less likely than SPM poverty. Appendix II Section 1 explains the HIPM MOOP limits in detail and Appendix II Section 2 provides a detailed example and step-by-step explanation of the HIPM implementation, including the MOOP capping procedures. Thus, when health insurance resources largely meet health insurance needs, we expect the HIPM poverty rate to be lower than the SPM rate, but when low-income families lack employer-provided health insurance, government insurance or subsidies for private insurance, we expect the HIPM poverty rate to be higher, perhaps much higher, than the SPM rate.

\section{Data}

We implement the HIPM with the data used by the Census Bureau for the OPM and SPM, the Current Population Survey (CPS) Annual Social and Economic Supplement (King et al. 2010, NBER n.d.). We calculate a pilot HIPM for the under-65 population, the main beneficiaries of health reforms. We dropped SPM “resource units” (e.g., families, Short 2013) that contain individuals over age 64 , reducing our sample from 3101 to 2582 , or by $16.7 \%$. Since the CPS does not allow identification of undocumented individuals, we also dropped SPM units that include one or more non-citizens who is either uninsured or has individually-purchased insurance, further reducing the analysis sample to 2504 , for a total sample reduction of $19.3 \%{ }^{4}$ Although our sample size limits precision, it is adequate for our purposes: demonstrating the practicality and some important applications of the HIPM.

\footnotetext{
${ }^{4}$ We could instead impute undocumented status (e.g., Kaiser Family Foundation 2013) and drop units with (imputed) undocumented persons who report individually-purchased insurance or who are uninsured.
} 


\section{Health Insurance Needs: The Basic Plan}

Determining which exchange plan is the Basic Plan involves judgment, as do many aspect of poverty measurement (NAS, 1995, p. 99). Since the ACA provides cost-sharing subsidies only for Silver plans (Claxton and Panchal 2015), and determines premium subsidies by ensuring that the second cheapest Silver tobacco-free plan premiums are affordable, under the ACA we would designate this benchmark plan as the Basic Plan. Each state's exchange database can provide the unsubsidized Basic Plan premium for a family. For our pilot HIPM for Massachusetts in 2010, we designated the cheapest Bronze Low plan the Basic Plan, since it was closest to today's ACA Silver. (Appendix II Section 3 describes our premium estimates and the Massachusetts plan data.)

Poverty is determined at the SPM-unit level, but health insurance plans are held by a variety of sub-units. For example, an unmarried couple living together forms an SPM unit but cannot receive exchange health insurance together. Within each SPM unit, we assign people covered by the same health insurance to a separate health insurance unit (HIU) and determine health needs and resources for each HIU, as described in Appendix II Section 4. We aggregate health insurance needs (and resources) over the HIUs to determine the SPM unit's HIPM poverty status.

\section{Health Insurance Resources}

For those provided health insurance by the government or employers, health insurance resources are the Basic Plan premium minus premium MOOP payments required to obtain that coverage. We do not allow the deduction to exceed what the family would have to pay for the Basic Plan; buying a more expensive plan cannot make a family poorer. What the family would 
have to pay to obtain the Basic Plan depends on their potential eligibility for public and private insurance and subsidies. Data limitations, however, constrain our ability to fully determine this amount and therefore, we make some assumptions. For a summary, see Appendix I, Table A1; for details see Appendix II.

Those who do not receive health insurance benefits have no health insurance resources to help them meet health insurance needs. If they are eligible for premium subsidies, however, we credit their resources with the subsidies. This includes the uninsured who have not heeded the mandate to purchase insurance and, therefore, not taken-up the subsidies for which they are eligible. However, in section V, we test the sensitivity of our results to this approach.

In states that have not expanded Medicaid eligibility, poor Medicaid-ineligible individuals are not eligible for subsidies (Rasmussen et al., 2013). However, their HIPM thresholds are defined because they are permitted to purchase unsubsidized plans on the exchanges.

In summary, health insurance resources are, for those provided health insurance plans:

\section{Health Insurance Resources $=$ Basic Plan Premium - premium MOOP (up to available Basic Plan premium MOOP),}

and for those not provided health insurance plans:

\section{Health Insurance Resources $=$ Subsidy to Premium, if eligible for premium subsidies $=0$, if ineligible}

Appendix I, Table A1 describes the determination of health insurance resources and caps for all insurance types. 


\section{Cost-sharing Needs}

While health insurance is the primary health care need, some health care needs are paid out-of-pocket, due to cost-sharing. Several approaches to cost-sharing are possible and none is without problems. ${ }^{5}$ Our treatment of cost-sharing currently hews closely to the SPM, but limits the deduction from resources of non-premium MOOP expenditures to the non-premium MOOP cap available with the Basic Plan.

In addition to cost-sharing expenditures, families may spend out-of-pocket on uncovered care (non-premium MOOP expenses), including out-of-network care. Because the Basic Plan covers all needed care, as determined politically and socially, ideally we would only deduct costsharing payments, not expenditures on uncovered care. However, the CPS does not currently distinguish cost-sharing expenditures from uncovered care and therefore we deduct all nonpremium MOOP up to a cap.

Both the ACA and the Massachusetts health reform cap nonpremium MOOP for all exchange plans: under the ACA, the maximum was $\$ 6,350$ for an individual and $\$ 12,700$ for a family in 2014; in 2010 Massachusetts, \$5000 and \$10,000, for the individual and family, respectively. Both laws reduce nonpremium MOOP caps further for those with low income, according to a sliding scale, implemented through government subsidies additional to the premium subsidies. Under the ACA, with Silver plans, lower nonpremium MOOP caps apply to those with incomes below 400\% of poverty (Focus on Health Reform 2011a, 2011b), and in Massachusetts, 300\% of poverty. (For example, in Massachusetts, the cap was \$2,300 for incomes up to $200 \%$ of the OPM threshold).

In summary, HIPM resources are:

\footnotetext{
${ }^{5}$ Korenman and Remler (2013) discuss alternative approaches to cost-sharing.
} 
HIPM Resources $=$ SPM resources $($ before MOOP deduction) + Health Insurance Resources -nonpremium MOOP (up to available Basic Plan cap)

\section{Poverty Status}

A family is poor if HIPM resources are insufficient to meet HIPM needs.

The following box summarizes and compares the Official, Supplemental and Health-Inclusive Poverty Measures. 


\section{Poverty Measure Concepts: Official, Supplemental and Health Inclusive}

\begin{tabular}{|c|c|c|c|}
\hline & Official Poverty Measure & Supplemental Poverty Measure & $\begin{array}{c}\text { Health Inclusive Poverty Measure } \\
\text { under the ACA }\end{array}$ \\
\hline $\begin{array}{l}\text { Measurement } \\
\text { Units }\end{array}$ & $\begin{array}{l}\text { Families or unrelated } \\
\text { individuals }\end{array}$ & $\begin{array}{l}\text { Families, including any coresident } \\
\text { unrelated children who are cared for by } \\
\text { the family (such as foster children) and } \\
\text { any cohabiters and their relatives, or } \\
\text { unrelated, noncohabiting individuals }\end{array}$ & SPM Uniti \\
\hline Non-Health Needs & $\begin{array}{l}\text { Three times cost of minimum } \\
\text { food diet in } 1963^{i 1}\end{array}$ & $\begin{array}{l}\text { The mean of expenditures on food, clothing, } \\
\text { shelter, and utilities (FCSU) over all two-child } \\
\text { consumer units in the 30th to } 36 \text { th percentile } \\
\text { expenditure range multiplied by } 1.2\end{array}$ & Same as SPM measure of non-health needs \\
\hline $\begin{array}{l}\text { Adjustments to } \\
\text { Non-health Needs }\end{array}$ & $\begin{array}{l}\text { Vary by family size, composition, } \\
\text { and age of householder }\end{array}$ & $\begin{array}{l}\text { Geographic adjustments for differences in } \\
\text { housing costs by tenure and a three- } \\
\text { parameter equivalence scale for family size } \\
\text { and composition }\end{array}$ & Same as SPM \\
\hline $\begin{array}{l}\text { Updating Non- } \\
\text { health Needs }\end{array}$ & Consumer Price Index: all items & $\begin{array}{l}\text { 5-year moving average of expenditures on } \\
\text { FCSU }\end{array}$ & Same as SPM \\
\hline Health Insurance Needs & Nonei & $\begin{array}{l}\text { Explicit: None } \\
\text { Implicit: All out-of-pocket expenditures on } \\
\text { insurance (premium MOOP) }\end{array}$ & $\begin{array}{l}\text { Explicit: Unsubsidized Premium of Basic Health } \\
\text { Insurance Plan }\end{array}$ \\
\hline $\begin{array}{l}\text { Cost-sharing and } \\
\text { Uncovered Health Care } \\
\text { Needs }\end{array}$ & Nonei & $\begin{array}{l}\text { Explicit: None } \\
\text { Implicit: All out-of-pocket expenditures on } \\
\text { care (non-premium MOOP) }\end{array}$ & $\begin{array}{l}\text { Explicit: None } \\
\text { Implicit: Capped out-of-pocket expenditures on care } \\
\text { (non-premium MOOP up to the cap available with } \\
\text { Basic Plan). }\end{array}$ \\
\hline
\end{tabular}




\section{Poverty Measure Concepts: Official, Supplemental and Health Inclusive}

\begin{tabular}{|l|l|l|l} 
Non-Health Resources & Gross before-tax cash income & $\begin{array}{l}\text { Sum of cash income, plus noncash benefits } \\
\text { that families can use to meet their FCSU } \\
\text { needs minus taxes (or plus tax credits), } \\
\text { minus work expenses and child support } \\
\text { paid to another household } \\
\text { minus out-of-pocket medical care and } \\
\text { insurance and Over-the-counter expenses } \\
\text { (MOOP) }\end{array}$ & $\begin{array}{l}\text { SPM Resource Measure without the MOOP } \\
\text { subtraction }\end{array}$ \\
\hline Health Insurance Resources & None & None & $\begin{array}{l}\text { For those who get private or public health } \\
\text { insurance benefits: Net Value of Health Insurance } \\
\text { Benefits } \\
\text { Specifically, unsubsidized premium of Basic Plan } \\
\text { minus actual premium MOOP (limited to premium } \\
\text { MOOP necessary to obtain Basic Plan). }\end{array}$ \\
\hline For those eligible for premium subsidies: subsidy \\
value.
\end{tabular}

\section{Source: The OPM and SPM descriptions are partly based on Short (2013, page 3).}

' However, health insurance needs \& resources are determined for Health Insurance Units, subunits of the SPM unit, then aggregated to SPM unit.

ii A small amount of out of pocket expenditures for health insurance and care (the 1963 budget share of approximately $4 \%$ of median income) is captured by the OPM needs threshold (NAS 1995, p. 226). 


\section{Implicit Thresholds and Poverty Gaps}

\section{Implicit Thresholds}

The SPM does not attempt to measure whether health insurance or care needs are met; it only aims to measure material (food, clothing, shelter and utilities) poverty. But it implicitly treats whatever health insurance and care a family purchases as essential—nondiscretionary—by deducting MOOP expenditures from resources. That approach is equivalent to adding all MOOP expenditures to the needs threshold and determining if (pre-deduction) resources are sufficient to meet the expanded needs threshold (e.g., Burtless and Siegel 2001).

We define a poverty measure’s Implicit Threshold as the measure’s explicit needs threshold plus the health deductions from resources that the measure treats as needs (i.e. nondiscretionary expenditures). The HIPM implicitly treats as health needs only basic health insurance and actual cost-sharing up to the Basic Plan cap. As noted, the SPM implicitly treats as health needs all insurance and care expenditures.

\section{Poverty gaps}

Researchers often measure the intensity of poverty by the poverty gap-the amount by which the poor's resources fall below the poverty threshold (Ben-Shalom, Moffitt and Scholz 2012; Ziliak 2004; Short 2011). We use the HIPM to estimate poverty gaps incorporating health needs. For each individual, we calculate the proportional poverty gap - the difference between his family’s needs and resources, as a proportion of needs (the HIPM Implicit Threshold). To calculate the mean poverty gap, we averaged individual gaps over all individuals in SPM units that have resources below HIPM needs threshold. 
Census reports show how government transfer programs reduce the SPM poverty rate by recalculating the rate as each transfer is excluded from income (e.g., US Census 2011; Short 2011). We estimate the effects of health insurance benefits on the HIPM gap in a similar way. We begin by including only pre-tax cash income in resources (OPM resources)—referred to as the "cash only" poverty rate and gap. We then add, in turn, non-health in-kind benefits plus net tax credits and various health insurance resources to calculate their poverty-reducing effects. We use the HIPM poverty gaps to show how health insurance benefits reduce poverty intensity and compare those effects to the combined effect of other transfer programs.

\section{Results: HIPM Poverty Rates and Gaps under the Massachusetts Health Reform Poverty rates}

For the under-65 population in 2010 Massachusetts the HIPM poverty rate of $12.2 \%$ is 1.3 percentage points lower than the $13.5 \%$ SPM poverty rate (Table 2, column 1, rows 2 and 4); for comparison, the OPM rate is $11.9 \%$ (row 1 ). The HIPM poverty rate is lower than the SPM rate because, in Massachusetts, the vast majority of people near the poverty line have their health insurance needs met and the HIPM limits MOOP deductions. (The effect on the SPM of deducting all MOOP is shown in the comparison of row 2 and row 3; it increases the SPM poverty rate by 3.1 percentage points, from $10.4 \%$ to $13.5 \%$.)

The other columns of Table 2 show a similar pattern of results for children and across family types: HIPM poverty rates fall zero to 2.7 percentage points below SPM rates (compare rows 2 and 4). The difference is largest for groups with high MOOP expenditures, as suggested by the difference between the SPM rate before and after MOOP deductions (row 2 vs. 3). For example, the SPM rate among persons in two-parent families is $8.0 \%$ before the MOOP 
deduction but $12.8 \%$ after. The HIPM, which limits the MOOP deduction, falls between these two: $10.1 \%$.

Table A3 in Appendix III presents suggestive evidence for the validity of the HIPM MOOP limits: on average, in 2010 Massachusetts, those classified as poor by the SPM but notpoor by the HIPM due to limits on MOOP deductions do not appear to be particularly needy and have fewer characteristics typically associated with poverty. For example, they are far less likely to receive public assistance such as Food Stamps/SNAP, to be uninsured, immigrants or to racially identify as black, and far more likely to be married, citizens or homeowners.

For the HIPM poverty rates reported in Table 2, the resources of the uninsured include the full value of the subsidies for which they are eligible. We test the sensitivity of our results to this assumption. We find that results do not change substantively when we instead crediting the uninsured with either no insurance subsidies or an implicit insurance value for free care ${ }^{6}$; the HIPM rate rises by only 0.36 percentage points (results available upon request). The results are not sensitive to these different assumptions because there were few uninsured persons in Massachusetts in 2010.

Although the SPM and HIPM for Massachusetts differ modestly, only the HIPM can show the direct impact of health transfers on poverty. Table 3 shows how the proportion poor (i.e., having insufficient resources to meet material and health insurance needs) falls as additional benefits are included in the resource measure (e.g., Ziliak 2004). (Figure 1 shows the health insurance impacts on poverty from Table 3.) Keep in mind that the needs threshold is the HIPM implicit needs threshold: the SPM needs threshold ("material" needs) plus health insurance needs

\footnotetext{
${ }^{6}$ Garthwaite, Gross and Notowidigdo (2015) find that each additional uninsured person increases hospital uncompensated care costs by $\$ 900$. We credit each uninsured HIU with free care (implicit insurance) resources of $\$ 900$, adjusting for age and family size with the equivalence formula we used to adjust Basic Plan insurance needs (see Appendix II, section 3).
} 
(unsubsidized premium of Basic Plan) plus a "need” for cost-sharing (non-premium MOOP expenditures up to the out-of-pocket maximum of the Basic Plan available to the family).

The first column of Table 3 shows results for the entire analysis sample. We begin by including only cash pre-tax income in resources (i.e., comparing OPM resources to the HIPM needs threshold). If only pre-tax cash income were available, the HIPM poverty rate would be 19.1\%. When we add non-health in-kind transfers and tax credits net of taxes paid (and make SPM adjustments to resources, other than the MOOP deduction), 19.2\% have material resources below the HIPM Implicit Threshold. (In this case, the poverty-increasing effects of taxes and child-care expenses offset the poverty-reducing effects of in-kind transfers and tax credits.) Employer-provided health insurance reduces the poverty rate by 3.1 percentage points to $16.1 \%$. Public health insurance reduces it another 3.3 points and premium subsidies another 0.6 percentage point. Together, public and private health transfers reduce poverty by seven percentage points. Of course, private health insurance transfers from employers are also partially subsidized by government, through the income tax exclusion.

This exercise is not an estimate of the causal impact of (eliminating) transfer programs, since it does not account for any behavioral adjustments as Sommers and Oellerich (2013) do for Medicaid and Ben-Shalom, Moffitt and Scholz (2012) do for a variety transfer programs. However, a HIPM could be used for such estimates. Two other limitations likely lead us to understate the impact of Massachusetts health reform on poverty. While we know whether a household member is covered by a policyholder outside the household, we cannot determine if they benefit from subsidies to the policyholder. More importantly, in contrast to our treatment of 
premium subsidies, we are unable to assess the impact on poverty of cost-sharing subsidies, including the income-related reductions in nonpremium MOOP caps. ${ }^{7}$

The remaining columns of Table 3 show transfers' impacts on poverty by family type and health insurance. Children’s health-inclusive poverty is reduced 2.6 percentage points by in-kind transfers and tax credits, 3.3 percentage points by employer-provided health insurance, 2.4 percentage points by public health insurance, and 0.8 percentage point by premium subsidies (column 2). The relatively large impact of transfers on child poverty reflects the targeting and greater generosity of benefits for families with children. Although the impacts of private and public health insurance appear comparable (3.3 and 3.2 percentage points), we should be careful in apportioning credit since employer coverage was stimulated by health reform (Gruber 2011; Long and Fogel 2014). In any case, the HIPM shows that, in Massachusetts, public and private health insurance benefits together account for a huge, one-third reduction in the child poverty rate (from 19.5 to 13.0), a major direct effect that is not detected by either the OPM or the SPM. Lone-adult (with no children) poverty is high compared to other groups. Yet lone-adults get little or no net poverty reduction from in-kind benefits and tax credits, and only a 1.7-point reduction from employer-provided health insurance. However, they benefit considerably from public health insurance, which lowers their poverty rate by 6.5 percentage points, and from premium subsidies, which lowers it by another one-half point. The HIPM thus illustrates that low-income adults without children benefit greatly from government transfers; the SPM and

\footnotetext{
${ }^{7}$ Cost-sharing subsidies work by increasing the actuarial value of the insurance plan, allowing insurers to reduce cost-sharing, such as co-pays and deductibles, flexibly. Therefore, we cannot know what cost-sharing terms low-income enrollees would have faced and, in turn, what their expenditures would have been, without the cost-sharing subsidies. Future research, however, could estimate the average change in cost-sharing expenditures and therefore the average change in HIPM resources.
} 
OPM do not, because transfers to this group are primarily health insurance (Medicaid) and premium subsidies.

In contrast to the experience of lone adults, non-health in-kind transfers and net tax credits account for large reductions in poverty rates (8.7 points) of persons in one-parent families (Bitler, Hoynes and Kuka 2014; Ben-Shalom, Moffitt, and Scholz 2012). Employer health insurance reduces the single-parent poverty rate by 2.8 points, reflecting substantial labor force participation (e.g., Meyer and Rosenbaum 2001); public health insurance accounts for another 3.5 point reduction.

Two parent-present families have low rates of “cash income” poverty (17.7\%). Yet government transfers lower their poverty markedly. Non-health in-kind benefits and tax credits reduce their poverty rate by 2.7 percentage points; employer health insurance another 1.9 points, public health insurance 2.2 points, and premium subsidies 0.8 points. The HIPM rate for individuals in two parent families is $10.1 \%$.

Similarly, two-adult (no child present) families also have low poverty rates, yet in-kind benefits and health insurance reduce their HIPM poverty. In-kind benefits and tax credits account for a 1.2 percentage point reduction, employer health insurance, 1.8 points, and government health insurance, a surprisingly large 4.1 points.

The final three columns of Table 3 show the effects of transfers on HIPM poverty by health insurance coverage. (Poverty is determined at the SPM-unit level, so each SPM unit may contain multiple health insurance units, which may have different insurance.) Among those with employer-provided insurance (column 7), after adding in-kind transfers and tax credits net of taxes paid (which increase poverty for this group), the poverty rate is 8.5 percent. Employer health insurance cuts their poverty markedly, to 4.8 percent. They benefit slightly (0.1 
percentage point) from government health insurance to other HIUs within the SPM unit and from premium subsidies ( 0.3 percentage points), resulting in a HIPM rate of 4.4 percent.

Not surprisingly, public health insurance reduces poverty of Medicaid beneficiaries greatly, 14.3 percentage points, which equals the reduction from (other) in-kind benefits and tax credits (column 8). Together, health insurance, in-kind transfers, and tax credits lift nearly 30 percent of this population out of poverty. Premium subsidies reduce poverty most among people covered by privately-purchased insurance (column 9), by 9.4 percentage points. In contrast, they get little net poverty reduction from in-kind transfers and tax credits, most likely because they have few children or their incomes are too high to qualify for substantial tax credits or in-kind transfers.

Because uninsured people get some free care, they have some implicit insurance, which reduces poverty relative to having no health insurance resources. The estimates in Table 3 ignore the value of free care. As a sensitivity analysis, therefore, we added a value for the implicit insurance of free care for everyone without employer-provided insurance. ${ }^{8}$ The results (available on request) suggested that free care would have approximately one-third the anti-poverty impact of the government health insurance and subsidies indicated in Table 3. This exercise make the assumption that, in the absence of all government health insurance transfers, everyone without employer insurance could get free care. Nonetheless, under this assumption, the analysis suggests that the impact of government health benefits on poverty may be only two-thirds as large as indicated by the figures in Table 3.

\footnotetext{
${ }^{8}$ We calculate the free care implicit insurance value as described in footnote 6 .
} 


\section{Poverty gaps}

We estimate HIPM poverty gaps using the HIPM Implicit Threshold, which includes material needs, health insurance needs, and cost-sharing (nonpremium MOOP) needs. We begin by calculating the gap based on pre-tax cash income only and then recalculate the gap as we add back resources. The population over which all average gaps are calculated is persons in families with pre-tax cash income below the HIPM Implicit Threshold.

Table 4 present poverty gaps for the entire sample (first column) and by health insurance type (columns 2 through 4). For all persons (column 1), the average poverty gap based on cash income alone was 43.7 percent—about half the health-inclusive poverty line. Adding in-kind transfers and tax credits net of taxes paid reduces the gap by 14.3 percentage points to $29.4 \%$; employer health insurance benefits reduce it by another 3.5 points; and public health insurance reduces the gap by a further 6.9 points, to $18.9 \%$. The greater effect on the poverty gap of public health insurance (6.9 percentage points) compared to private health insurance (3.5 points) stands in contrast to their roughly equal effect on the poverty rate (Table 3), reflecting the targeting of public insurance on the poorest persons. Premium subsidies reduce the poverty gap from 18.9 to 17.2 percent. In sum, non-cash transfers including health insurance reduced the cash poverty gap by nearly 2/3 (from 43.7 to 17.2 percent). This two-thirds reduction in the poverty gap considerably exceeds the one-third reduction in the poverty rate because many transfers move families toward but not over the poverty threshold.

On average, poor individuals covered by employer-provided insurance have a relatively small “cash only” health-inclusive poverty gap (34.5\%). In-kind transfers and tax credits reduce the gap 5.5 points; employer insurance reduces it by another 12.6 points to $16.5 \%$, and public insurance and premium subsidies reduce it to $16.0 \%$. Medicaid recipients have a large initial 
HIPM poverty gap (48.6\%). In-kind transfers and tax credits reduce the gap by more than twenty points (to $27.2 \%$ ); public health benefits reduce it by another 12.1 points to $14.9 \%$.

Although few people who buy individual insurance are cash-income poor, among cashpoor individual purchasers of insurance, the poverty gap is large, 50\%. After all in-kind transfers and tax credits, their poverty gap remains high, 51.5\%. However, premium subsidies reduce their gap by nearly 20 percentage points, from $51.5 \%$ to $32.4 \%$. Thus, although poor persons who buy individual insurance have cash incomes sufficient to meet only half their basic material and health insurance needs, thanks mainly to Massachusetts health insurance reform, they have resources (including premium subsidies) sufficient to meet over two-thirds of their needs. Neither the OPM nor SPM can account for these substantial direct impacts of premium subsidies on poverty for this group.

\section{VI: Caveats, Critiques and Practical Difficulties of the HIPM}

Although the HIPM has many advantages, it also has its weaknesses. We have already discussed implementation difficulties related to undocumented persons. Six conceptual issues require further discussion.

\section{Overvaluation of health insurance}

Crediting resources with the full cost of health insurance (unsubsidized premium) might over-value health insurance. First, low-income individuals could value health insurance at less than its cost (NAS 1995). Second, the US health care system may be inefficient, raising costs without raising benefits commensurately (e.g., Cutler and Ly 2011). These issues complicate incorporating health insurance benefits in income inequality measures, as in Burkhauser, 
Larrimore and Simon (2012, 2013), CBO (2012) and Aaron and Burtless (2014); see also Meyer and Sullivan (2012a), Ruggles (1990).

Overvaluing health insurance, however, cannot affect the HIPM poverty rate, because health insurance resources are never valued at more than health insurance needs. Therefore, health insurance resources alone can never remove a "materially poor" person from poverty. (Overvaluing health insurance would, however, inflate the HIPM poverty gap and overstate the impact of health insurance benefits on the gap.) The cost of health insurance may be unnecessarily high and lower-income individuals may value it at less than cost, but if they need insurance and do not have the resources to meet that need, they have unmet needs and are poor.

\section{Single vs. Multiple Measures}

One reason the NAS narrowed the focus of poverty measurement to "material" poverty was the lack of fungibility of health insurance benefits—-that health insurance cannot be used to meet material needs. Although the HIPM rate does not suffer from this fungibility problem, nonetheless, multiple measures can provide a more complete picture of different dimensions of need (Blank 2008).

In fact, the NAS panel (1995, page 237) recommended a split measure; a measure of material poverty, like the SPM, and a separate measure of health care economic risk. They favored separate measures because, "To do otherwise is to overwhelm the poverty measure with operational and conceptual difficulties." We believe this justification, while compelling at the time, is no longer. As we have argued, ACA-like reforms enable a conceptually valid combined measure of health and material poverty, if one accepts that the health care need of the poor is a 
basic health insurance plan. And our Massachusetts pilot demonstrates its feasibility.

Furthermore, as Bernheim notes:

I suspect that we have focused on poverty rates primarily to satisfy the demands of politicians and the press, who generally seem to limit their attention to single numbers. To the extent that economists wish to affect the policy process, it may be necessary to cater to the demand for oversimplification; thus....if politicians insist on using a single number, we should make sure that it is the best number possible.

On the same point, Meier and Wolfe (2012) argue that a

... split approach is superior to a combined approach; it allows the capture of both the medical care burden and medical care risk perspectives in poverty measurement. In making this argument, we note the loss of simplicity offered by a single measure and recognize that, for policy purposes, the need for simplicity may dominate the wish for greater accuracy. Even in this view, we still favor the calculation of a separate medical care economic risk index to capture current and changing medical risk as a separate and important indicator of well-being and deprivation.

We agree that, while a separate medical care economic risk index would be valuable, it does not reduce the importance of creating the best possible single poverty measure (Garner, Short and Gudrais 2013).

\section{The Basic Plan, Take-up Failures and Poor Decisions}

Our HIPM is based on the idea that MOOP expenditures—premium and nonpremiumare discretionary if they result from choosing a plan other than the Basic Plan. In some respects, this approach is uncharitable since choosing health insurance is difficult, due to plan and system complexity and the need to consider health and financial circumstances. For example, each year the second cheapest Silver plan (the Basic Plan) may change, reducing subsidies available for last year's plan. Nonetheless, for the purpose of poverty measurement, if the Basic Plan is universally available and people have sufficient resources, how can we say that they lack resources to meet their basic health insurance needs? Instead, we advocate policies that directly 
address complexity, such as making the low MOOP-risk insurance option the default plan for lower-income persons.

Similarly, some may object to our counting as resources the premium subsidies for which families are eligible, even when they remain uninsured. (As described previously, we conducted a sensitivity analysis to this assumption.) But for poverty measurement if the Basic Plan is universally available, there is a mandate to purchase insurance, and people have sufficient resources, how can we say that they lack adequate resources to meet their basic health insurance needs? This approach is similar to the Census Bureau's procedure for imputing taxes owed or credits received based on income, rather than using actual taxes paid and credits received, though research continues on this issue (Short, Donahue and Lynch, 2012).

\section{The Insured Don't Get Needed Care and Get Unnecessary Care}

Whether spending on nonpremium MOOP up to the Basic Plan nonpremium MOOP cap is discretionary depends on the "discretionarity” of the care purchased. The NAS panel implied that nearly all care is essential in citing as examples of nondiscretionary care "elective cosmetic surgery...extra laboratory tests or ineffective drugs” (pp.232-236). At the other extreme, Cogan (1995) described "health as an economic good, responsive to both income and price changes.”

To the extent that care is discretionary, we would not want to deduct the resulting cost-sharing expenditures. Different approaches to cost sharing merit additional research.

A different problem is that cost-sharing dissuades some people with the Basic Plan from receiving needed care. The HIPM would not measure this unmet need. However, the SPM will miss more unmet health care needs than the HIPM because the SPM is not designed to measure health needs and does not consider insurance a need. More importantly, the political process determines the Basic Plan and the means-tested subsidies to assure affordability. Critics may feel 
the political process erred, resulting in plans with excessive cost-sharing or insufficient subsidies. But the HIPM accepts the Basic Plan and associated subsidies as the politically-determined standard of need and affordability. It is not clear that there is a valid alternative. In fact, "needed care” has no generally agreed upon conceptual definition and would be impossible to measure directly in social surveys such as the CPS. Our approach to cost-sharing in the HIPM is practical and builds directly on the SPM.

\section{Risk-segmentation and Basic Plan Premium}

The HIPM's health insurance need is the price of the Basic Plan available for purchase on the exchange in the rating area, the price that any marginal (unsubsidized) customer would pay. That price reflects the risk pool of those in fact covered by exchange plans. ${ }^{9}$ If everyone in an area, including those with Medicaid or employer-provided insurance, purchased insurance on the exchange, then the risk pool would change and so, likely, would the Basic Plan premiums. Nonetheless, we use the current Basic Plan price as the "need" for everyone, irrespective of their actual insurance coverage or risk profile.

We do so for three reasons. First, the premium data are actually available. Another choice would require imputation and additional assumptions. Second, these premiums reflect what is available for purchase by anyone lacking similar or better health insurance (except the undocumented). Third, and most importantly, this choice should not affect the HIPM poverty rate, because the same values of basic insurance go into needs and resources. For example, because Medicaid fully meets health insurance needs, we also add the Basic Plan premium to resources for those covered by Medicaid. Since we add the same value to needs and resources,

\footnotetext{
${ }^{9}$ Premiums available to specific individuals or families also depend on government regulations, such as community rating rules, risk corridors, risk adjustment and so on.
} 
any "errors" due to risk segmentation will appear both in needs (denominator) and resources (numerator) and leave the poverty rate estimate unaffected.

Poverty gap calculations (Table 4) and accounting exercises (Table 3) would, however, change somewhat if we used a different value for the plan premium and needs for the segmented Medicaid population (or other segmented populations). Specifically, our estimates would likely understate the impact of Medicaid on HIPM poverty rates and gaps to the extent that the Medicaid population is systematically higher risk.

\section{Over-the-counter medications.}

The SPM includes over-the-counter (OTC) medications in the MOOP deduction (Short 2013). While some OTC drugs are essential (e.g., children's acetaminophen), others are not (e.g., brand name ibuprofen). Moreover, since spending (in dollars) on OTC drugs is not likely skewed or high variance, it might be better to incorporate it into the HIPM by expanding the SPM material threshold beyond food, clothing, shelter and utilities. ${ }^{10}$ Sensitivity analysis shows that HIPM poverty estimates are not sensitive to including them; the HIPM increased by only 0.3 points when we deducted OTC expenses.

\section{VII: Conclusions}

The NAS Report considered a HIPM desirable but unattainable. Despite concerns about ignoring an important necessity and devaluing health insurance, the report recommended excluding health care and insurance from the revised poverty measure's threshold and resources. Yet the NAS Report (p. 69) anticipated that “....as changes are made to the US system of health

\footnotetext{
${ }^{10}$ Long-term care expenses are excluded from both the SPM and HIPM and are not measured by the CPS.
} 
care, it will be important to reevaluate the treatment of medical care expenses in the definition of family resources...” That day is here for the US and arrived in Massachusetts several years ago. The HIPM conceptualizes health insurance as the core health need. If instead the core health needs were conceptualized as a need for health care, it would be exceedingly difficult to measure. In writing about the development of a health care economic risk measure, Meier and Wolfe (2012) and Meier (2014) describe many of the challenges. The "tails" of health care expenditures are extremely long. Moreover, an individual's expenditure depends on extensive clinical detail. Therefore, one needs health care databases with large sample sizes and much clinical detail to measure health care expenditures—or needs—with any precision. The expenditure distribution and its relationship to clinical and other characteristics change over time as technology changes. The purpose of health insurance, however, is to deal with those tails. If everyone has insurance, their health needs can be met, no matter how large the expenditures or what new technologies arise.

The HIPM has several advantages. Unlike the SPM, the HIPM directly measures unmet health insurance needs—and thus unmet needs for care and risk reduction. Although the SPM can measure the impact of health insurance on poverty through any reductions in MOOP (e.g., Sommers and Oellerich 2013), it cannot measure the risk reduction among the healthy (with little MOOP), nor improved access to health care provided by health insurance. If a family foregoes health care because it is uninsured, the SPM does not capture the unmet need. If Medicaid expansions or the ACA allow the family to obtain health care, the SPM will register no direct poverty decrease. The SPM also does not show a healthy uninsured family to have unmet insurance needs. If they gain Medicaid coverage, the SPM registers no poverty decrease. 
Put differently, a HIPM can more fully reflect the difficult tradeoffs between material well-being on the one hand, and health insurance and health care on the other. Many Americans face those tradeoffs because the US health care system requires significant expenditures on both premiums and cost-sharing. Although the SPM may properly capture how meeting health care needs compromises material well-being, the SPM cannot capture how meeting material needs may compromise adequate health care. Thus, poverty measures that ignore health, or separate measures of material deprivation and health care/insurance deprivation, are ill-suited to today's US health care system.

As a consequence, some uninsured people mandated to purchase even highly subsidized insurance under the ACA will be measured by the SPM as poorer. When they pay even modest premiums, MOOP increases and SPM resources decrease, but the SPM assigns no value to the highly subsidized insurance they receive. Thus, if basic health insurance and health care are needs, the SPM misses and a HIPM captures important ways that Medicaid, the ACA and employer-provided insurance reduce poverty. A HIPM could also allow international comparisons of poverty that explicitly account for cross-national differences in health benefits.

Though based on small samples and several approximations, our pilot HIPM suggests that public health insurance benefits account for a three-percentage point reduction in the poverty rate for the under-65 in Massachusetts and premium subsidies account for another point. Impacts on poverty gaps are even larger. Government health insurance accounts for a 2.4 percentage point reduction in the child poverty rate in Massachusetts and premium subsidies another 0.8 percentage point. Among those with individual insurance, the premium subsidies reduce HIPM poverty from $36.6 \%$ to $27.2 \%$. Given the large expenditures on low-income persons through programs such as Medicaid, their substantial impact on poverty should not be surprising. 
Nonetheless, the result is novel because other poverty measures do not directly value health insurance in resources and needs.

We believe a HIPM will provide a more accurate assessment of the direct impact of the ACA on poverty than any of the currently available measures. By providing a single measure of poverty that validly incorporates health needs, it could show the anti-poverty impacts of policy differences, such as differences between states that expand Medicaid eligibility and those that do not. Thus, a HIPM can show the impact of the ACA and other major health insurance programs across states, nationally and, in principle, internationally. 


\section{References}

Aaron, Henry and Gary Burtless. 2014. "Potential Effects of the Affordable Care Act on Income Inequality.” Brookings. Available at http://www.brookings.edu/research/papers/2014/01/potentialeffects-affordable-care-act-income-inequality-aaron-burtless

Richard Bavier. 1998. Medical needs and the poverty thresholds. March. http://www.census.gov/hhes/povmeas/publications/medical/bavier4.html

Ben-Shalom, Yonatan, Robert Moffitt, and John Karl Scholz. 2012. An Assessment of the Effectiveness of Antipoverty Programs in the United States. In Philip N. Jefferson, ed. The Oxford Handbook of the Economics of Poverty. New York: Oxford University Press.

Bernheim, B. Douglas. 1998. Comment on Deaton and Paxson’s “Measuring poverty among the elderly,” in D.A. Wise, ed. Inquiries in the economics of aging. Chicago: NBER/University of Chicago Press.

Betson, David M. 2000. Response to Bavier's Critique of the NRC Panel’s Recommendations. November. www.census.gov/hhes/povmeas/publications/wp-medical.html

Bitler, Marianne, Hilary Hoynes, and Elira Kuka. 2014. Do In-Work Tax Credits Serve as a Safety Net? NBER Working Paper No. 19785. January

Blank, Rebecca M. 2008. Presidential address: How to Improve Poverty Measurement in the United States. Journal of Policy Analysis and Management 27(2): 233-254. 
Blinder, A. 1985. Commentary on Ellwood and Summers. In U.S. Department of Commerce, Bureau of the Census, Proceedings of the Conference on the Measurement of Noncash Benefits, Volume I. Williamsburg, VA. December 12-14: pp. 28-31.

Burkhauser, R.V., J. Larrimore and K.I. Simon. 2012. "A “Second Opinion” on the Economic Health of the American Middle Class" National Tax Journal, 65: 7-32.

Burkhauser, R.V., J. Larrimore and K. Simon. 2013. Measuring the impact of valuing health insurance on levels and trends in inequality and how the Affordable Care Act of 2010 could affect them. Contemporary Economic Policy 31(4): 779-794.

Burtless, G. and S. Siegel. 2001. Medical Spending, Health Insurance, and the Measurement of American Poverty. Focus 21(3): 17-22.

Caswell, Kyle J. and Brett O’Hara. 2010. Medical Out-of-Pocket Expenses, Poverty, and the Uninsured SEHSD Working Paper 2010-17. U.S. Census Bureau, Washington, D.C. December.

Center for Medicare and Medicaid Services (CMS). 2003. Clarifying Policies Related to the Responsibilities of Medicare-Participating Hospitals in Treating Individuals with Emergency Medical Conditions. https://www.cms.gov/Regulations-andGuidance/Legislation/EMTALA/Downloads/CMS-1063-F.pdf

Center for Medicaid and Medicare Services (CMS). n.d. Health Insurance Marketplace Public Use Files. https://www.cms.gov/CCIIO/Resources/Data-Resources/marketplace-puf.html 
Claxton, Gary and Nirmita Panchal. 2015. "Cost-Sharing Subsidies in Federal Marketplace Plans.” http://kff.org/health-costs/issue-brief/cost-sharing-subsidies-in-federal-marketplaceplans/

Cogan, John F. 1995 Dissent. Appendix A, in Citro, C. and R. T. Michael, eds. 1995. Measuring Poverty: A New Approach. National Research Council of the National Academy of Sciences. National Academy Press.

Congressional Budget Office (CBO). 2012. The Distribution of Household Income and Federal Taxes, 2008 and 2009. http://www.cbo.gov/sites/default/files/cbofiles/attachments/43373-06-11$\underline{\text { HouseholdIncomeandFedTaxes.pdf }}$

Corbett, T. 1999. Poverty: Improving the measure after 30 years. Focus 20(2): 51-55.

Cutler, David M. and Dan P. Ly. 2011. The (paper) work of medicine: Understanding international medical costs. Journal of Economics Perspectives 25(2): 3-25.

Daniels, Norman, Brendan Saloner and Adriane H. Gelpi. 2009. “Access, Cost, And Financing: Achieving An Ethical Health Reform.” Health Affairs 28(5): w909-16.

Dillman, J., B. Mancas, M. Jacoby and L. Ruth-Sahd. 2014. A review of the literature: differences in outcomes for uninsured versus insured critically ill patients: opportunities and challenges for critical care nurses as the Patient Protection and Affordable Care Act begins open enrollment for all Americans. Dimensions of Critical Care Nursing 33(1): 8-14.

Ellwood, David T. and Lawrence H. Summers. 1985. "Measuring income: What kind should be in?“ in U.S. Department of Commerce, Bureau of the Census, Proceedings of the Conference on the Measurement of Noncash Benefits, Volume I. Williamsburg, VA. December 12-14, pp. 8-27. 
Focus on Health Reform. 2011a. Summary of New Health Reform Law. Last modified April 15, 2011.

Focus on Health Reform. 2011b. What the Actuarial Values in the Affordable Care Act Mean. April 2011.

Garner, Thesia I, Kathleen Short and Marissa Gudrais. 2013. The Supplemental Poverty Measure Under Alternate Treatments of Medical Out-of-Pocket Expenditures. December 19. Paper Presented to the Allied Social Science Association (ASSA) Meetings, Philadelphia, PA. Jan. 4, 2014. https://www.aeaweb.org/aea/2014conference/program/retrieve.php?pdfid=327

Garthwaite, Craig, Tal Gross and Matthew J. Notowidigdo. 2015. Hospitals as Insurers of Last Resort. National Bureau of Economic Research working paper no. 21290.

Gruber, Jonathan. 2011. Massachusetts Points the Way to Successful Health Care Reform,” Journal of Policy Analysis and Management, 30(1), Winter, p. 184-192.

Institute of Medicine (IOM). 2002. Care Without Coverage: Too Little, Too Late. Washington, DC: The National Academies Press.

Kaiser Family Foundation. 2013. Issue Brief. Technical Appendix B: Immigration Status Imputation. October

King, Miriam, Steven Ruggles, J. Trent Alexander, Sarah Flood, Katie Genadek, Matthew B. Schroeder, Brandon Trampe, and Rebecca Vick. 2010. Integrated Public Use Microdata Series, Current Population Survey: Version 3.0. [Machine-readable database]. Minneapolis: University of Minnesota. 
Long, Sharon K., and Paul B. Masi. 2009. Access and Affordability: An Update on Health Reform in Massachusetts, Fall 2008. Health Affairs 28(4):w578-87.

Long, Sharon K. and Ariel Fogel. 2014. Health insurance coverage and health care access, use, and affordability in Massachusetts: An update as of Fall 2012. Report to the Blue Cross Blue Shield of MA Foundation. March.

Martin, Anne B., Micah Hartman, Joseph Benson, Aaron Catlin and the National Health Expenditure Accounts Team. 2015. “National Health Spending In 2014: Faster Growth Driven By Coverage Expansion And Prescription Drug Spending” Health Affairs. December: published online prior to print publication.

Meier S. and B. Wolfe. 2012. Conceptual Framework for Measuring Medical Care Economic Risk. In Medical Care Economic Risk: Measuring Financial Vulnerability from Spending on Medical Care. Panel on Measuring Medical Care Risk in Conjunction with the New Supplemental Income Poverty Measure, M.J. O’Grady and G.S. Wunderlich, Eds. Committee on National Statistics, Division of Behavioral and Social Sciences and Education, and Board on Health Care Services, Institute of Medicine. Washington, DC: The National Academies Press, pp. 225-266.

Meier, Sarah. 2014. “Measuring Medical Expenditure Risk: Implications for the Development of a Measure of Medical Care Economic Risk.” Mayo Clinic Manuscript. 
Meyer, Bruce D. and Dan Rosenbaum. 2001. "Welfare, the Earned Income Tax Credit, and the Labor Supply of Single Mothers," Quarterly Journal of Economics, 116(3):1063-1113.

Meyer, Bruce D. and James X. Sullivan. 2012a. "Winning the War on Poverty from the Great Society to the Great Depression.” Brookings Papers on Economic Activity Fall, pp. 133-183.

Moon, Marilyn. 1993. Incorporating Health Issues in the Measurement of Poverty. Urban Institute.

National Academy of Sciences (NAS).1995. Measuring Poverty: A New Approach. National Research Council of the National Academy of Sciences. Citro, C. and R. T. Michael, eds. Washington, DC: National Academy Press.

NBER. nd. National Bureau of Economic Research CPS Supplements. www.nber.org/data/current-population-survey-data.html

Nyman, John A. 2003. The Theory of Demand for Health Insurance. Stanford, CA: Stanford University Press.

Nyman, John. 2004. “Is Moral Hazard Inefficient?” Health Affairs 23(5): 194-199.

Pascale, Joanne, Michel Boudreaux, and Ryan King. 2014. Understanding the New Current Population Survey Health Insurance Questions. US Census RESEARCH REPORT SERIES Survey Methodology \#2014-02. https://www.census.gov/srd/papers/pdf/RSM2014-02.pdf

Rasmussen, Petra W., Sara R. Collins, Michelle M. Doty and Tracy Garber. 2013. In States’ Hands: how the Decision to Expand Medicaid Will Affect the Most Financially Vulnerable Americans. September. The Commonwealth Fund. Vol. 23. Pub. 1702. 
Ruggles, Patricia. 1990. Drawing the Line: Alternative Poverty Measures and Their Implicatinos for Public Policy. Washington, D.C.: The Urban Institute Press.

Short, Kathleen S. 2011. The Supplemental Poverty Measure: Examining the Incidence and Depth of Poverty in the U.S. Taking Account of Taxes and Transfers. US Census Bureau SEHSD working paper \# 2011-20 June 3

Short, Kathleen S. 2013. The Research Supplemental Poverty Measure: 2012. Current Population Reports P60-247, U.S. Census Bureau. November.

Short, Kathleen, Dennis Donahue \& George Lynch. 2012. EITC Estimates in the CPS ASEC Simulations of After-Tax Income Hispanic Population. SEHSD Working Paper \# 2012-19. August.

Sommers, Benjamin D. and Donald Oellerich. 2013. The Poverty-Reducing Effect of Medicaid. Journal of Health Economics 32: 816-832.

Sommers, Benjamin D., Sharon K. Long, and Katherine Baicker. 2014. Changes in Mortality After Massachusetts Health Care Reform: A Quasi-experimental Study. Annals of Internal Medicine 160(9): 585-593.

US Bureau of the Census. 2011. Income, poverty and health insurance coverage in the United States: 2010. Current Population Reports. P60-239. September.

Ziliak, James P. 2004. Filling the Poverty Gap, Then and Now. Discussion Paper. University of Kentucky Center for Poverty Research. Revised January 2004 
Table 1: Illustrative Calculation of the SPM and HIPM for Two Hypothetical Families

\begin{tabular}{|l|l|l|l|}
\hline $\begin{array}{l}\text { Line } \\
\text { No. }\end{array}$ & Feeds & Family A & Family B \\
\hline$(1)$ & Material needs (SPM threshold) & 20,000 & 20,000 \\
\hline$(2)$ & Health Insurance Needs (Basic Plan) & 10,000 & 10,000 \\
\hline & Resources & & \\
\hline$(3)$ & Income (SPM resources) & 22,000 & 22,000 \\
\hline$(4)$ & Health insurance resources provided & None & $\begin{array}{l}\text { Medicaid } \\
\text { policy, no } \\
\text { MOOP } \\
\text { premium } \\
\text { payment } \\
\text { required. } \\
\text { Value = } \\
\text { Basic Plan } \\
(10,000) .\end{array}$ \\
& & & Not poor \\
\hline$(5)$ & HIPM Resources (line 3 + line 4) & Not poor & 32,000 \\
\hline$(6)$ & HIPM Poverty Threshold (line 1 + line 2) & 22,000 & 30,000 \\
\hline (7) & HIPM Poverty status: line (5) vs. line (6) & $\mathbf{3 0 , 0 0 0}$ & Not Poor \\
\hline
\end{tabular}

Note: Neither family has any premium or nonpremium MOOP. 


\begin{tabular}{|l|l|c|c|c|c|c|}
\hline \multicolumn{5}{|c|}{ Table 2: Official, Supplemental and Health Inclusive Poverty Rates, Massachusetts, 2010} \\
SPM Units with All Persons Under Age 65 \\
Poverty Rates (\%) for Persons, By Family Type
\end{tabular}

Notes:

Sample weighted using CPS March Supplement person weights.

OPM: Official Poverty Measure

SPM: Supplemental Poverty Measure

MOOP: Medical Out of Pocket Expenses

HIPM: Health Inclusive Poverty Measure 


\begin{tabular}{|c|c|c|c|c|c|c|c|c|c|}
\hline \multirow[b]{2}{*}{ Resources } & \multirow[b]{2}{*}{ All } & \multicolumn{5}{|c|}{ Family Type } & \multicolumn{3}{|c|}{ Health Insurance Type $^{1}$} \\
\hline & & Children & $\begin{array}{l}\text { Lone } \\
\text { Adult } \\
\text { SPMUs }\end{array}$ & $\begin{array}{l}\text { Persons in } \\
\text { One-Parent } \\
\text { SPMUs }\end{array}$ & $\begin{array}{c}\text { Persons in } \\
\text { Two- } \\
\text { Parent } \\
\text { SPMUs }\end{array}$ & $\begin{array}{c}\text { Persons in } \\
\text { Two- } \\
\text { Adult } \\
\text { SPMUs }\end{array}$ & Employer $^{2}$ & Medicaid $^{3}$ & $\begin{array}{l}\text { Individual } \\
\text { Purchase }\end{array}$ \\
\hline & $(1)$ & $(2)$ & (3) & (4) & (5) & $(6)$ & $(7)$ & $(8)$ & (9) \\
\hline “Cash” only (OPM resources) & 19.1 & 22.1 & 28.2 & 42.0 & 17.7 & 14.2 & 6.0 & 68.8 & 27.2 \\
\hline $\begin{array}{l}\text { Add: in-kind government transfers \& } \\
\quad \text { tax credits, less taxes, etc. }^{4} \\
\text { (SPM resources, pre-MOOP deduction) }\end{array}$ & 19.2 & 19.5 & 30.2 & 33.3 & 15.0 & 13.0 & 8.5 & 54.6 & 36.6 \\
\hline Add: employer health insurance & 16.1 & 16.2 & 28.5 & 30.5 & 13.1 & 11.2 & 4.8 & 54.0 & 36.6 \\
\hline Add: government health insurance & 12.8 & 13.8 & 22.0 & 27.0 & 10.9 & 7.1 & 4.7 & 39.3 & 36.6 \\
\hline $\begin{array}{l}\text { Add: MA health insurance subsidies } \\
\text { (HIPM) }\end{array}$ & 12.2 & 13.0 & 21.5 & 27.0 & 10.1 & 7.1 & 4.4 & 39.3 & 27.2 \\
\hline Unweighted sample count & 2504 & 819 & 222 & 182 & 1183 & 292 & 1757 & 369 & 56 \\
\hline
\end{tabular}

1. The "all" column includes persons covered by types of insurance not shown separately: Medicare $(<65)$, VA and other veterans programs, those covered by individuals outside households and uninsured individuals. Public health insurance benefits or subsidies to persons outside the household to the benefit of the sample member cannot be measured. Poverty is determined at the SPM-Unit level. SPM Units are divided into multiple health insurance units (HIUs) according to members’ HI coverage. Our HI units differ from CPS/IPUMS HI units. See Appendix II Section 4 for details.

2. For Medicaid: the OPM rate is 53, the SPM rate is 41.5;

3. For Employer Provided Insurance: the OPM rate is 2.0; the SPM rate is 5.5 .

4. This also includes other SPM adjustments to resources such as deducting necessary childcare expenses. 


\begin{tabular}{|l|c|c|c|c|}
\hline $\begin{array}{l}\text { Table 4: Effects of Public and Private Transfers on Health Inclusive Poverty Gaps, Massachusetts, } 2010 \\
\text { Individuals in SPM Units with All Persons Under Age 65 } \\
\text { By Health Insurance Type }\end{array}$ \\
\hline \begin{tabular}{l|c|c|c|} 
All \\
Resources
\end{tabular} & Employer & Medicaid & $\begin{array}{c}\text { Individual } \\
\text { Purchase }\end{array}$ \\
\hline & $(1)$ & $(2)$ & $(3)$ & $(4)$ \\
\hline Cash only (OPM resources) & 43.7 & 35.4 & 48.6 & 49.4 \\
\hline $\begin{array}{l}\text { Add: in-kind government transfers \& tax } \\
\text { credits, less taxes, etc. } \\
\text { (SPM resources, pre-MOOP deduction) }\end{array}$ & 29.4 & 29.1 & 27.2 & 51.8 \\
\hline Add: employer health insurance & 25.8 & 16.5 & 27.1 & 51.8 \\
\hline $\begin{array}{l}\text { Add: government health insurance } \\
\text { Add: MA health insurance subsidies } \\
\text { (HIPM) }\end{array}$ & 18.9 & 16.3 & 15.0 & 51.5 \\
\hline \begin{tabular}{l} 
Unweighted sample count \\
\hline
\end{tabular} & 48.2 & 16.0 & 14.9 & 32.4 \\
\hline
\end{tabular}

1. Note the "all" column includes persons covered by types of insurance not shown separately: Medicare (<65), VA and other veterans programs, those covered by individuals outside households and uninsured individuals. Public health insurance benefits or subsidies to persons outside the household to the benefit of the sample member cannot be measured.

2. Poverty is determined at the SPM-Unit level. SPM Units are divided into multiple health insurance units (HIUs) according to members' HI coverage. Our HI units differ from CPS/IPUMS units. See Appendix II Section 4 for details.

3. This also includes other SPM adjustments to resources such as deducting necessary childcare expenses. 
Figure 1:

Impact of Health Insurance \& Mass. Premium Subsidies on HIPM Poverty Rates

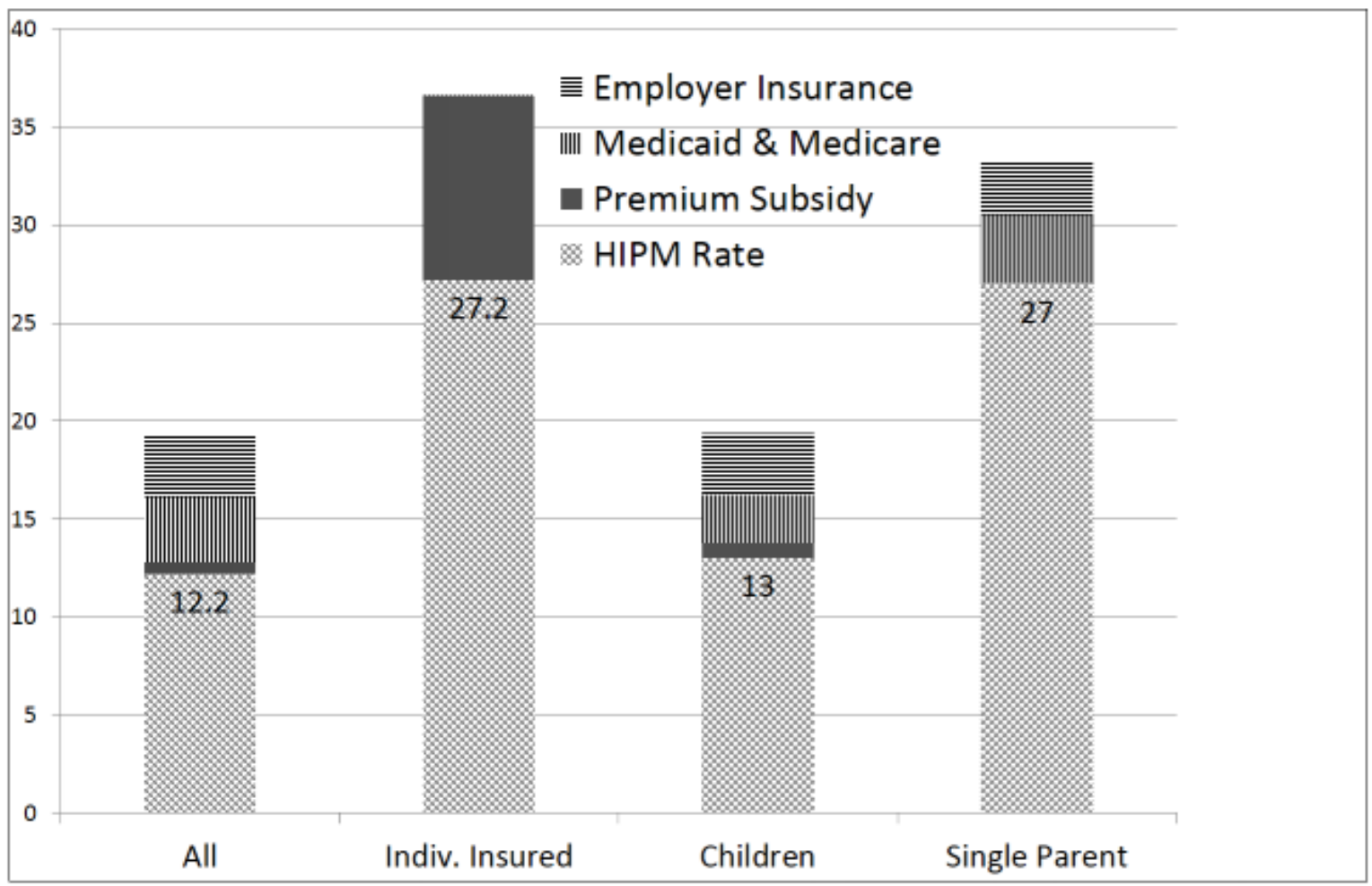

\section{Notes:}

1. "Single Parent" is persons in single parent families; Indiv. Insured are individuals in health insurance units (subunits of SPM family units) who purchase insurance as individuals or families, rather than as part of a group plan or government insurance program.

2. The number in each bar is the HIPM poverty rate for the group.

3. See Table 2 for additional information and figures for other groups. 
Appendix I. Table A1: Health Insurance Resources \& MOOP Deductions by Health Insurance Type

\begin{tabular}{|c|c|c|}
\hline $\begin{array}{l}\text { Health Insurance } \\
\text { Type }\end{array}$ & Health Insurance Resources & Nonpremium MOOP Deduction \\
\hline Employer Provided & $\begin{array}{l}\text { Basic Plan Unsubsidized Premium } \\
\text { - Actual Premium (up to BP } \\
\text { premium) }\end{array}$ & $\begin{array}{l}\text { Actual nonpremium MOOP } \\
\text { (up to BP nonpremium MOOP cap, with no }_{\text {income-related reductions) }^{1}}\end{array}$ \\
\hline $\begin{array}{l}\text { Individually } \\
\text { Purchased }\end{array}$ & $\begin{array}{l}\text { Subsidy to premium } \\
\text { (unless family member has } \\
\text { employer provided insurance) }{ }^{2}\end{array}$ & $\begin{array}{l}\text { Actual nonpremium MOOP } \\
\text { (up to BP nonpremium MOOP cap; income- } \\
\text { related reductions apply unless family member } \\
\text { has employer-provided insurance) } \\
\end{array}$ \\
\hline $\begin{array}{l}\text { Covered by Someone } \\
\text { Outside SPM Unit }\end{array}$ & Basic Plan Unsubsidized Premium ${ }^{4}$ & $\begin{array}{l}\text { Actual nonpremium MOOP } \\
\text { (up to BP nonpremium MOOP cap; income- } \\
\text { related reductions apply unless family member } \\
\text { has employer-provided insurance) } \\
\text { 34 }\end{array}$ \\
\hline Full-year Medicaid & Basic Plan Unsubsidized Premium ${ }^{5}$ & $\begin{array}{l}\text { Actual nonpremium MOOP } \\
\text { (up to low Medicaid nonpremium MOOP cap) }\end{array}$ \\
\hline Veterans Affairs & Basic Plan Unsubsidized Premium & $\begin{array}{l}\text { Actual nonpremium MOOP } \\
\text { (up to BP nonpremium MOOP cap; ; income- } \\
\text { related reductions apply unless family member } \\
\text { has employer-provided insurance) }{ }^{8}\end{array}$ \\
\hline $\begin{array}{l}\text { Medicare (non- } \\
\text { elderly) }\end{array}$ & $\begin{array}{l}\text { Basic Plan Unsubsidized Premium } \\
\text { - Actual Premium up to MA-PD } \\
\text { BP premium }\end{array}$ & $\begin{array}{l}\text { Actual nonpremium MOOP } \\
\text { (up to MA-PD nonpremium MOOP cap) }^{10}\end{array}$ \\
\hline Part-year Medicaid & $\begin{array}{l}\text { Basic Plan Unsubsidized Premium } \\
\text { pro-rated to number of months } \\
\text { covered by Medicaid }\end{array}$ & $\begin{array}{l}\text { Actual nonpremium MOOP } \\
\text { (up to BP nonpremium MOOP cap; income- } \\
\text { related reductions apply unless family member } \\
\text { has employer-provided insurance) }\end{array}$ \\
\hline Uninsured & Subsidy to premium ${ }^{12,2}$ & $\begin{array}{l}\text { Actual nonpremium MOOP } \\
\text { (up to BP nonpremium MOOP cap; income- } \\
\text { related reductions apply unless family member } \\
\text { has employer-provided insurance) }\end{array}$ \\
\hline
\end{tabular}

Notes:

BP = Basic Plan; MOOP = Medical Out-of-Pocket Expenditures; MA-PD = Medicare-Advantage-Prescription Drug;

IPUMS-HIU = Integrated Public Use Microsample Health Insurance Unit

${ }^{1}$ Nonpremium MOOP caps set by law.

${ }^{2}$ Subsidy is the difference between the BP unsubsidized premium and maximum premium MOOP allowed, based on household income and the sliding scale set by law. Family (IPUMS-HIU) income-based maximum MOOP premiums apply even if only part of the household purchases insurance on the exchange. We assume that those in a family with someone with employer provided insurance are not eligible for subsidized premiums and are therefore capped at the unsubsidized BP premium. See Appendix II for details and citations.

${ }^{3}$ Sliding-scale for nonpremium MOOP caps is also determined by family (IPUMS-HIU) income.

${ }^{4}$ For those covered by someone outside the SPM unit, we cap the entire MOOP subtraction at the BP cap.

${ }^{5}$ For states that require Medicaid recipients to pay premium MOOP, premium MOOP payments up to the maximum amount required would be deducted.

${ }^{6}$ States determine nonpremium MOOP caps for Medicaid.

${ }^{7}$ VA eligible do not pay any premiums.

${ }^{8}$ VA cost-sharing depends on priority statuses such as service-related disability and other factors not available in our data. Veterans who are already VA qualified are not eligible for the exchange subsidies, including the income-based nonpremium MOOP reductions. However, since they are eligible for low VA cost-sharing, we cap their MOOP expenditures at the BP caps.

${ }^{9}$ We assume Medicare recipients' BP is the cheapest available MA-PD plan. The MA-PD plan premium is the Part-B premium plus the additional MA-PD premium, if any. In this study we assume no additional MA-PD plan beyond Part-B premium is required since that is currently the case. See Appendix II Section 5.

${ }^{10}$ MA-PD nonpremium MOOP caps did not exist in Massachusetts in 2010. Nationally, they started for medical care in 2011 after the ACA but still do not exist for prescription drug coverage. See Appendix II Section 5. Since we have only non-elderly Medicare recipients, we use the BP caps.

${ }^{11}$ We capped nonpremium MOOP for those with part-year Medicaid at the full-year BP cap. 
${ }^{12}$ Although the uninsured do not receive premium subsidies, they could have had them and we treat them as government resources available to meet health insurance needs. See text for sensitivity analyses. 


\section{Appendix II.}

\section{Limiting MOOP Deductions}

The HIPM is based on the idea that all needed health care is covered and made affordable by the Basic Plan and subsidies available for it. Therefore, the HIPM should not show a family as poorer because it buys a more expensive plan than the Basic Plan. Nor should the HIPM show a family as poorer because it spends more on health care than the Basic Plan's cap on costsharing expenditures. (This could happen even to a family with the Basic Plan if they purchase uncovered procedures or out-of-network care.) Limiting (capping) premium and nonpremium MOOP deductions ensures these conditions. In this appendix we describe the procedures for limiting these deductions. Appendix I Table A1 describes how to determine the deduction limits for each insurance type.

The HIPM credits the resources of those with health insurance benefits from government or employers with the net value of their insurance: the Basic Plan minus out-of-pocket premium payments. Since only for groups with insurance benefits is net insurance value credited, only those groups have premium MOOP deducted. Therefore, the limit to the premium MOOP deduction applies only to those groups. For those with employer-provided or governmentprovided insurance:

\section{Health Insurance Resources $=$ Basic Plan Premium - premium MOOP (up to amount required for Basic Plan)}

The premium MOOP deduction is limited to what the family would be required to pay for the Basic Plan. For many families, that limit is simply the unsubsidized premium for the Basic Plan. However, if a family would be eligible for premium subsidies, then the limit would be lower by the amount of the premium subsidies. 
Subsidies are not available to those with "qualified and affordable” employer-provided insurance. Nor are subsidies available to their families, if the employer plan is qualified and affordable to the employee only—the so-called "family glitch" (Brooks 2014). Because we cannot identify whether plans are qualified, we assume that all employer provided plans are qualified and affordable, and that anyone in the same family (i.e., same IPUMS HIU; see Appendix II Section 4) of someone with employer provided insurance is not eligible for subsidies. This assumption could lead us to understate somewhat the impact on poverty of premium subsidies.

To address cost-sharing needs, the HIPM follows the SPM and deducts from resources whatever families of any insurance type spend on nonpremium MOOP. However, we limit that deduction to the cap available to the family under the Basic Plan:

HIPM Resources $=$ SPM resources $($ before MOOP deduction) + Health Insurance

\section{Resources - nonpremium MOOP (up to available Basic Plan cap)}

If a family could have had cost-sharing subsidies that reduced their maximum cost-sharing expenditures, we limit the deduction to that maximum. As for premium subsidies, we assume that the lower nonpremium MOOP caps are not available to anyone with employer-provided insurance or to their families (see Appendix II Section 1). The Appendix I Table A1 describes how to determine the nonpremium MOOP deduction caps for each insurance type.

HIPM health resources, needs, and caps are first determined and applied at the HIU level. The HIU health needs and resources are aggregated to the SPM-unit level and combined with material needs and resources to determine HIPM poverty status.

Limits to premium and nonpremium MOOP deductions are the only HIPM changes that can increase the likelihood of poverty under the HIPM relative to the SPM. In 2010 
Massachusetts, where the vast majority of people have their health insurance needs met, limiting MOOP deduction made the HIPM poverty rate higher than the SPM poverty rate.

\section{2, Step-by-step Example of Implementing HIPM Poverty Status and Gaps}

We illustrate the step-by-step procedure of implementing HIPM poverty status and poverty gaps and provide comparisons with the OPM and SPM. This section is meant to help those familiar with poverty measurement with details necessary for implementation.

Example Family C has employer-provided insurance for which it pay an out-of-pocket premium. Details and calculation steps are shown in Table A2. We determine the family's poverty status according to the HIPM, OPM and SPM, though for comparability, we use the SPM measure of material needs ( $\$ 20,000$, line 1$)$ for all three measures.

\section{The basic poverty status calculation for each measure compares resources to the} appropriate needs threshold. When we do this, Family C is poor according to both the OPM and the SPM. For OPM status, Family C lacks pre-tax cash income (OPM resources) to meet its material needs (line $3<$ line 1). But its SPM resources are higher, due to including tax credits (net of taxes paid) and in-kind transfers (line 4) other than health insurance. If the family's only resources were SPM resources before MOOP deductions, it would not be poor since those resources exceed the SPM threshold (line 5 > line 1). However, the SPM deducts all MOOP expenditures (line 8, the sum of line 6 and line 7) from SPM material resources. So the family is poor according to the SPM, because, after subtracting MOOP expenditures, its resources are less than its material needs (line $9<$ line 1 ). Thus, if there were no MOOP deduction, the family would not be poor. 
Table A2: HIPM Calculations for Family with Employer-Provided Insurance Benefits and MOOP Expenses

\begin{tabular}{|c|c|c|}
\hline $\begin{array}{l}\text { Line } \\
\text { No. }\end{array}$ & & Family C \\
\hline (1) & $\begin{array}{l}\text { Needs } \\
\text { Material needs (SPM threshold) }\end{array}$ & 20,000 \\
\hline \multirow[t]{2}{*}{ (2) } & Health Insurance Needs (BCP) & 10,000 \\
\hline & Resources & \\
\hline (3) & Cash income, pre-tax (OPM resources) & 18,500 \\
\hline (4) & In-kind benefits (non-health) and tax credits net of taxes paid & 3,500 \\
\hline (5) & Income (SPM resources before MOOP deductions) (line 3 +line 4) & 22,000 \\
\hline (6) & Health insurance resources provided & $\begin{array}{l}\text { Employer-provided } \\
\text { insurance } \\
\$ 3,000 \text { premium MOOP } \\
\text { required }\end{array}$ \\
\hline (7) & Actual nonpremium MOOP & 1,500 \\
\hline (8) & Actual total MOOP (line $6+$ line 7 required MOOP) & 4,500 \\
\hline \multirow[t]{3}{*}{ (9) } & SPM resources after MOOP deduction (line 5 - line 8) & 17,500 \\
\hline & SPM Poverty Status (line 9 versus line 1 ) & Poor \\
\hline & HIPM & \\
\hline (10) & BCP nonpremium MOOP cap & 9,000 \\
\hline (11) & Net Health Insurance Resources (line 2 - line 6) & 7,000 \\
\hline (12) & HIPM Poverty Threshold (line $1+$ line 2 ) & 30,000 \\
\hline \multirow[t]{3}{*}{ (13) } & HIPM Resources = (line $5+$ line 12$)-\min$. of (line 7 and line 11$)$ & 27,500 \\
\hline & HIPM Poverty status: line (13) vs. line (14) & Poor \\
\hline & Implicit Thresholds & \\
\hline (14) & SPM Implicit Threshold (line $1+$ line 8) & 24,500 \\
\hline (15) & HIPM Implicit Threshold (line $13+$ min. of (line 7 and line 11) & 31,500 \\
\hline
\end{tabular}


How does the HIPM poverty calculation differ from the SPM? To determine HIPM poverty status, we compare HIPM resources to the HIPM threshold. The HIPM threshold is simply the SPM threshold plus basic health insurance needs (the Basic Plan), or \$30,000 (line 12). For resources, the HIPM includes material resources before the MOOP deduction (line 5) and health insurance resources. Family C's health insurance resources are the net value of their employer-provided health insurance: the basic plan premium $(\$ 10,000)$ minus a required premium MOOP payment of \$3,000, or \$7,000 (line11). Since HIPM resources $(\$ 22,000+$ $\$ 7,000-\$ 1,500=\$ 27,500$, line 13) fall short of the HIPM threshold the family is HIPM-poor. Family C's employer-provided health insurance largely, but not completely, meets their health insurance needs. In this case, the SPM and HIPM poverty status are the same because the HIPM adds the $\$ 10,000$ Basic Plan to needs, adds something less than $\$ 10,000$ to resources to reflect required premium payments, and the HIPM caps on MOOP subtractions did not bind: the $\$ 9,000$ cap on the deduction for nonpremium MOOP (line 10) exceeds the actual nonpremium MOOP of $\$ 1,500$ (line 7). But in other cases, those who are not provided health insurance (like Family A in Table 1) will be poorer according to the HIPM than the SPM. In addition, those who have health insurance but high premium or nonpremium MOOP can be poorer according to the SPM than the HIPM if MOOP spending is above the HIPM limits and, thus, the MOOP caps bind.

In summary, the HIPM poverty rate can be either higher or lower than the SPM rate. However, importantly, the HIPM's inclusion of health insurance benefits as resources can never move a family out of poverty because health insurance resources can never exceed health insurance needs (or, therefore, be used to meet non-health needs). However, by limiting 
allowable MOOP deductions, the HIPM can classify as nonpoor a family that the SPM classifies as poor.

\section{Implicit Threshold}

The SPM Implicit Threshold adds all MOOP expenditures (line 8) to the explicit material SPM threshold (line 1) to get \$24,500 (line 14). Implicitly, the SPM assumes that all MOOP expenditures are needed (non-discretionary). Family C is SPM poor because its (pre-deduction) SPM resources of \$22,000 (line 5) are less than its implicit needs of \$24,500 (line 14). Similarly, the HIPM Implicit Threshold is the explicit HIPM threshold (for material and health insurance needs) plus the allowed deduction for cost-sharing needs. For Family C, the HIPM Implicit Threshold adds allowed nonpremium MOOP expenditures of $\$ 1500$ (the minimum of line 7 and line 10) to the explicit material HIPM threshold of $\$ 30,000$ (line 12) to get $\$ 31,500$ (line 15). Family C is HIPM poor because its pre-deduction resources of $\$ 22,000$ plus the net value of its employer-provided insurance (\$7,000)—\$29,000—falls short of its HIPM Implicit Threshold of $\$ 31,500$ : $\$ 20,000$ for material needs, $\$ 10,000$ of resources for health insurance needs, and $\$ 1,500$ for cost-sharing needs. We use the implicit thresholds to calculate poverty gaps with the HIPM.

Poverty Gaps

A family’s poverty gap is one minus the ratio of its resources to the HIPM Implicit Threshold. If the only resources were cash income, the cash-only poverty gap would be 1- (cash income/HIPM Implicit Threshold). For Family C, this would be:

Cash poverty gap $=1-[18,500 / 31,500]=1-.59=0.41$ or $41 \%$. 
Pre-tax cash income fills 59 percent of Family C’s basic material, health insurance and costsharing needs, leaving a gap of 41 percent. We continue to show how different resources fill the health inclusive poverty gap.

We next add \$3,500 of in-kind benefits and tax credits net of taxes paid and recalculate the gap:

$$
1-[(18,500+3,500) /(31,500)]=1-.70=0.30,
$$

so in-kind transfers close 11 percentage points or more than a quarter of Family C's initial poverty gap. Finally, adding health insurance resources of 7,000, the $\$ 10,000$ Basic Plan less the $\$ 3,000$ premium:

$1-[(18,500+3,500+(10,000-3,000)) /(31,500)]=1-0.92=0.08$.

Therefore, together, health insurance, in-kind transfers and net tax credits nearly close Family C's cash-only poverty gap, leaving the family's resources only eight percent below the HIPM Implicit Threshold. If their cash resources fell below, but their after-transfer resources exceeded, the HIPM Implicit Threshold, we would set their post-transfer poverty gap to zero for calculation of the average gap, calculating the average gap over the same baseline population with cash income below the HIPM Implicit Threshold.

\section{Premium Estimates and Other Data for 2010 Massachusetts $^{11}$}

Unlike the ACA, the Massachusetts health reform had separate exchanges for subsidized and unsubsidized insurance plans, Commonwealth Care and Commonwealth Choice, respectively. We lack data on the full cost of the subsidized plans (unsubsidized premiums) and so use the premiums on the unsubsidized exchange (Commonwealth Choice). If the unsubsidized

\footnotetext{
${ }^{11}$ We thank Keith Ericcson for providing us selected premium data from the 2010 unsubsidized exchange (Commonwealth Choice). We thank Michael Norton for providing us with data on Commonwealth Care (subsidized exchange) and Medicaid for 2010 Massachusetts, specifically, the nonpremium MOOP caps for Medicaid and schedules relating out-of-pocket premiums and nonpremium MOOP caps to (adjusted) income for 2010.
} 
exchange had a healthier risk pool than the subsidized exchange, we underestimate premiums and understate health insurance needs, relative to what they would have been under the ACA. No analogous problem exists under the ACA since there is one exchange for subsidized and unsubsidized plans.

The HIPM requires identification of the Basic Plan and its premium for all Health Insurance Units (HIUs). The premiums will depend on the number of people in the HIU and their ages, as well as their geographic location. Under the ACA, tobacco use also affects premiums, but we consider a Tobacco-Free plan the basic need. Although the exchanges have all the necessary information needed to calculate a HIPM, we did not have access to that information for Massachusetts in 2010. Instead, we predicted premiums by family size and age of members using limited information from 2010 Massachusetts as we now explain.

Starc and Ericcson (2013) collected premium data for 2010 Massachusetts for the zipcode 02130 for 35-year old adults and any family members. We selected the cheapest bronze low plan as our Basic Plan since that plan was closest in actuarial richness to the ACA silver plan. We extracted information for the cheapest silver plan for a variety of ages and family sizes from the 2014 Massachusetts health exchanges for zipcode 02130, and fit a regression model to predict variation by age and family size. ${ }^{12}$ Using the predicted premium regression equation, anchored with the premiums from Ericcson and Starc, for each HIU, we predicted 2010 Massachusetts the premium of the cheapest low bronze plan. Our prediction model overstates age-variations in premiums in 2010 because the ACA regulations in operation in 2014 allowed a 3:1 maximum variation by age, while the 2010 Massachusetts regulations allowed only a 2:1 maximum variation by age.

\footnotetext{
${ }^{12}$ Predictors were the total number of children (20 years old or less) and the total number of adults in 5-year age bands (21-24, 25-29, etc.).
} 
Since the public-use version of the CPS does not include detailed geographic identifiers, we assumed that the 02130 premiums applied throughout. Premiums may be lower outside the greater Boston area.

\section{Assigning Individuals to Health Insurance Units within Households}

In order to calculate health insurance needs and resources, individuals must be grouped into health insurance units (HIUs). For HIPM purposes, those who receive health insurance together must be put into the same HIU.

We use the following rules to construct our HIUs and to define HIU "types":

- Each person reported as having Medicare is put in his/her own one-person HIU of type "Medicare."

- Employer-provided insurance policyholder and all dependents of that policy are put in the same HIU with health insurance type "employer-provided insurance."

- Individually purchased insurance policyholder and all dependents of that policy are in the same HIU with health insurance type "individually purchased insurance."

- Each person reported as having full-year Medicaid coverage is given health insurance type "full-year Medicaid.” Everyone in the same family (i.e., IPUMS HIU) with full-year Medicaid is put in the same HIU. In addition, children (under 18-year-old) with no other health insurance coverage who have a parent with full-year Medicaid are considered to have full-year Medicaid and placed in the same HIU as that parent. The assumption is that they could obtain Medicaid.

- Those who report any type of Veterans Affairs (VA) coverage (either VA Milt or VA Champus) are given health insurance type "VA" and put in their own, one-person, HIU.

- Each person reported as being covered by someone outside the household is considered to have HI type of "covered outside the household." Everyone in the same family (i.e., IPUMS HIU) covered outside the household is put in the same HIU. For example, a mother and her child both covered outside the household are in the same HIU, but a 
grandmother or roommate in the same SPM unit, also covered by someone outside the household, would be placed in separate HIUs.

- Those who report being covered by Medicaid for part of the year and report no other insurance are included in the same HIU of type "part-year Medicaid.” All those in the same family (i.e., IPUMs HIU) who report being part-year Medicaid are put in the same HIU.

- Everyone who is reported to be uninsured is given HI type "uninsured." All those in the same family (i.e., IPUMs HIU) who report being uninsured are put in the same HIU.

In cases where more than one type of insurance is reported, we assigned insurance type using the following order of priority: Medicare, employer-provided, individually purchased, fullyear Medicaid, VA, covered by someone outside the household, uninsured, part-year Medicaid. The health insurance questions on the new CPS will improve classification of insurance coverage (Pascale, Boudreaux and King 2014)

Premium subsidies may not be available to families of those with employer-provided health insurance if the employer-provided insurance is considered qualified and if coverage for the employee only is considered affordable — the "family glitch” (e.g., Brooks 2014). Since the CPS does not collect information about whether an employee plan is qualified and affordable to the employee only, we assume it is qualified and affordable and exclude such family members from premium subsidies.

SHADAC (2012) have constructed similar family units (also referred to as HIUs) for the IPUMS CPS; we will refer to them as “IPUMS HIUs.” Their IPUMS HIUs are based on family definitions for exchange and Medicaid rules. Our HIUs are often identical to IPUMS HIUs but differ when actual health insurance coverage differs among those in the same IPUMS HIU. Examples include: a wife with employer provided insurance and a husband on Medicare; a 
mother with employer provided insurance and children on exchange plans. The income of the IPUMS HIU determines our HIU's Medicaid and subsidy eligibility. While this may be confusing, it best captures reality: the entire family (IPUMS HIU) income determines the maximum premium payments (and, therefore, subsidies) for those actually covered by the same insurance (our HIU).

\section{Plan Full Cost and MOOP caps for under-65 Medicare beneficiaries}

Medicare beneficiaries, even those under 65, are not eligible for the exchanges. However, the Medicare Advantage Prescription Drug (MA-PD) plans meet nearly all the HIPM criteriaand so we use them as the Basic Plan for Medicare beneficiaries. These plans cover all necessary care, including prescription drugs, and, often even vision and dental. Their premiums are not risk rated. As of 2011, (nonpremium) MOOP for all medical care provided by MA-PD plans is capped at $\$ 6700$ (the $95^{\text {th }}$ percentile in costs in the traditional Medicare fee-for-service) and CMS encourages plans to lower the cap to $\$ 3400$, the $85^{\text {th }}$ percentile in the traditional Medicare program (Biles, Nicholas and Guterman 2006).

Present MA-PD plans fall short of our ideal Basic Plan because they lack an explicit cap on prescription drug nonpremium MOOP spending. (The Federal government funds and regulates the prescription drug coverage part of MA-PD plans separately, as part of the prescription drug (Part D) benefits.) However, several features of the plans and of Federal regulations reduce prescription drug nonpremium MOOP and create de facto caps. First, for all beneficiaries, once the catastrophic level of nonpremium MOOP is reached (currently $\$ 4700$ ), cost sharing is substantially reduced (MedPAC, 2012). Second, the Medicare Part D low-income subsidy program reduces or eliminates cost-sharing for Medicare beneficiaries with low income and low assets (Summer, Hoadley and Hargrave, 2010). Third, many MA-PD plans offer 
enhanced prescription drug coverage that eliminates the deductible and substantially reduces copays, particularly for generic drugs, meaning high prescription drug expenditures are, to some extent, discretionary. Finally, even conventional Part D plans are reducing the extensive prescription drug coverage cost-sharing in the “donut-hole,” eliminating it by 2020. So we expect MA-PD enhanced coverage could have even less cost-sharing (Focus on Health, 2011).

In Massachusetts in 2010, there was no legally required cap for MA-PD plans for out-ofpocket spending on medical care. Nonetheless, we apply the exchange caps to the Medicare beneficiaries. This is justified for several reasons and is unlikely to affect our illustrative estimates. First, as noted, most MA-PD plans have limited cost-sharing. Second, poor Medicare beneficiaries are protected through Medicaid and other programs. Third, there are only 62 Medicare beneficiaries in our analysis sample.

To construct the HIPM, we must identify a particular MA-PD plan as the Basic Plan. The terms and features of MA-PD plans vary considerably. Plans may trade off premium MOOP and nonpremium MOOP. Major metropolitan areas have plans with little or no premium above the Part B premium and little, if any cost-sharing. In fact, an MA-PD plan with no additional premium above the Part-B premium was available in 2014 in zipcode 02138. . We assume that the same was true in 2010. Such information can be obtained by searching the CMS interactive Plan Finder Web Site https://www.medicare.gov/find-a-plan/questions/home.aspx). For national implementation, some rural areas have no HMO MA-PD plans, but even in these areas it should be possible to identify a PPO or fee-for-service MA-PD plan as the Basic Plan.

A further complication is that the premiums paid by Medicare beneficiaries for MA-PD plans are far below the unsubsidized premium, since the government contribution is so large. Unfortunately, we cannot determine the government contribution to Medicare for under-65 
beneficiaries alone. Therefore, we cannot calculate the unsubsidized premium for the MA-PD plan for our sample, and instead use the exchange Basic Plan as a proxy for it in needs. For those with Medicare, the Basic Plan is an MA-PD plan. In 2010, MA-PD plans had no nonpremium MOOP caps; those were instituted as part of the ACA legislation. We nonetheless apply the Basic Plan nonpremium MOOP caps. For this illustration with the under-65, we treat the Basic Plan unsubsidized premium as the unsubsidized premium (full cost) for the under-65 Medicare beneficiaries. This problem is eliminated when the HIPM is implemented for both those over and under 65, because the average government contribution can be calculated for both groups together. 


\section{Appendix III: Differences between HIPM and SPM Poor}

The HIPM and SPM poverty populations have very similar characteristics because the two measures assign the same poverty status to nearly the entire population; the HIPM and SPM poverty rate in Massachusetts differs by only one to two percentage points. The difference in the rate results nearly exclusively from 38 SPM-poor persons reclassified as “non-poor” by the HIPM. (Only two HIPM-poor persons are classified as not poor by the SPM.) As explained in the text, since the low-income population of Massachusetts is well-insured, the reclassification results from HIPM caps of the MOOP deductions. Thus we refer to the HIPM poor who are not SPM poor as those "capped out" of poverty and we refer to people classified poor by both measures as “other poor persons.” Table A3 presents descriptive statistics for the 38 capped out persons (column 2) and 310 other poor persons (column 1).

Relative to other poor persons, those capped-out of poverty by the HIPM have far higher average cash income $(\$ 42,422$ vs. $\$ 15,656)$ and far higher SPM resources pre-MOOP deduction (cash income plus in-kind transfers plus tax credits minus tax payments: $\$ 39,525$ vs. \$18,896). But the capped out report nearly $\$ 16,000$ in MOOP compared to only $\$ 2,800$ among other poor persons. After MOOP deductions, average SPM resources of both groups (third row) falls below the average SPM needs threshold (fourth row), since both groups are poor according to the SPM.

Statistics in the remainder of the table suggest that, in addition to much higher cash income, the capped out are far less likely to have characteristics associated with poverty than other poor persons. For example, they are less likely to receive SNAP (Food Stamps); 21\% percent of the capped out live in a family that gets SNAP vs. 36\% among other poor persons. The capped out are also more likely to own a home (only $46 \%$ are renters vs. $64 \%$ among other poor persons). Fully $75 \%$ of the capped out are persons in two-parent-present families compared 
to just $34 \%$ of other poor persons; none of the capped are single parent families compared to about $14 \%$ among other poor persons. The capped out are more likely to have employerprovided health insurance ( $54 \%$ vs. $25.5 \%$ ), less likely to be covered by Medicaid ( $29 \%$ vs.48\%) and less likely to be uninsured (5.0\% vs. 8.5\%). Finally, the capped out are less likely to be noncitizens ( $4.2 \%$ vs. $12.7 \%)$ or racially identify as black ( 0.0 vs. 19.3$)$, characteristics typically correlated with poverty. However, the capped out somewhat more likely to be children (42.3\% vs. $35.9 \%)$.

While based on small samples and limited by imperfectly-measured income (Meyer and Sullivan 2012b; Meyer, Mok and Sullivan, 2015), the figures in Table A3 suggest that those capped out of poverty by the HIPM MOOP limitation appear much less needy than other poor persons; this provides evidence to support the validity of the HIPM, particularly (in this case) the HIPM caps on MOOP. 
Table A3: Means and proportions for persons, weighted

\begin{tabular}{|c|c|c|}
\hline Characteristic & $\begin{array}{l}\text { SPM poor \& } \\
\text { HIPM poor } \\
\text { “other poor” } \\
(1)\end{array}$ & $\begin{array}{l}\text { SPM poor but } \\
\text { not HIPM poor } \\
\text { “capped out” } \\
(2)\end{array}$ \\
\hline Unweighted sample count & 310 & 38 \\
\hline \multicolumn{3}{|l|}{ Income and related } \\
\hline Cash Income before taxes & $\$ 16,656$ & $\$ 42,422$ \\
\hline SPM Resources, before MOOP Deduction & $\$ 18,896$ & $\$ 39,525$ \\
\hline SPM Medical expenditures (MOOP) & $\$ 2,812$ & $\$ 15,916$ \\
\hline SPM Resources, after MOOP Deduction & $\$ 16,084$ & $\$ 23,609$ \\
\hline SPM needs threshold & $\$ 25,360$ & $\$ 26,353$ \\
\hline SPM SNAP (Food Stamps) & $36.2 \%$ & $21.3 \%$ \\
\hline \multicolumn{3}{|l|}{ SPM Housing tenure } \\
\hline Owns, no mortgage & $7.4 \%$ & $4.2 \%$ \\
\hline Owns, with mortgage & $28.3 \%$ & $49.5 \%$ \\
\hline Rents & $64.2 \%$ & $46.2 \%$ \\
\hline \multicolumn{3}{|l|}{ SPM Family type } \\
\hline Single Parent & $13.8 \%$ & $0.0 \%$ \\
\hline Two Parent & $33.8 \%$ & $75.1 \%$ \\
\hline Lone Adult & $21.9 \%$ & $16.4 \%$ \\
\hline Adult Couple (no children present) & $8.4 \%$ & $8.5 \%$ \\
\hline Other & $22.1 \%$ & $0.0 \%$ \\
\hline \multicolumn{3}{|l|}{ Health Insurance Unit Type } \\
\hline Medicaid & $47.8 \%$ & $29.2 \%$ \\
\hline Employer & $25.5 \%$ & $54.0 \%$ \\
\hline Outside household & $9.1 \%$ & $11.8 \%$ \\
\hline Medicare & $3.5 \%$ & $0.0 \%$ \\
\hline Individually purchased & $5.4 \%$ & $0.0 \%$ \\
\hline Uninsured & $8.5 \%$ & $5.0 \%$ \\
\hline \multicolumn{3}{|l|}{ Demographic Characteristics } \\
\hline Noncitizen & $12.7 \%$ & $4.2 \%$ \\
\hline Black racial identification & $19.3 \%$ & $0.0 \%$ \\
\hline SPM number of persons in unit & $3.15 \%$ & $3.47 \%$ \\
\hline SPM number of children & $1.18 \%$ & $1.64 \%$ \\
\hline Age (years) & $30.2 \%$ & $30.7 \%$ \\
\hline Child & $35.9 \%$ & $42.3 \%$ \\
\hline
\end{tabular}




\section{Appendix References}

Biles, Brian, Lauren Hersch Nicholas and Stuart Guterman. 2006, Medicare Beneficiary Out-ofPocket Costs: Are Medicare Advantage Plans a Better Deal? Commonwealth Fund pub. 927 Vol. 19. May, 1-16.

Brooks, Tricia. 2014. "The Family Glitch." Healthy Policy Briefs. November 10. Available at http://www.healthaffairs.org/healthpolicybriefs/brief.php?brief_id=129

Ericson, Keith M.M. and Amanda Starc. 2013. How product standardization affects choice:

Evidence from the Massachusetts health insurance exchange. NBER Working Paper 19527. October.

Focus on Health Reform. 2011. Summary of New Health Reform Law. Last modified April 15, 2011.

Medicare Payment Advisory Commission (MedPAC). 2012. "Status Report on Part D, with Focus on Beneficiaries with High Drug Spending” in Medicare Payment Report to Congress, March 2012.

Meyer, Bruce. D. and James X. Sullivan. 2012b. Identifying the Disadvantaged: Official Poverty, Consumption Poverty and the New Supplemental Poverty Measure. Journal of Economic Perspectives 26(3): 111-136.

Meyer, Bruce D., Wallace K.C. Mok and James X. Sullivan. 2015. Household Surveys in Crisis. NBER Working Paper No. 21399. July. 
Pascale, Joanne, Michel Boudreaux, and Ryan King. 2014. Understanding the New Current Population Survey Health Insurance Questions. US Census RESEARCH REPORT SERIES Survey Methodology \#2014-02. https://www.census.gov/srd/papers/pdf/RSM2014-02.pdf

SHADAC (State Health Access Data Assistance Center). 2012. “Defining 'Family’ for Studies of Health Insurance Coverage.” May. Available at http://www.shadac.org/publications/definingfamily-studies-health-insurance-coverage.

Summer, Laura, Jack Hoadley and Elizabeth Hargrave. 2010. The Medicare Part S Low-Income Subsidy Program: Experience to Date and Policy Issues for Consideration. http://kff.org/medicare/issue-brief/the-medicare-part-d-low-income-subsidy/ 